\title{
The CatSper channel modulates boar sperm motility during capacitation.
}

Alejandro Vicente-Carrillo, Manuel Álvarez-Rodríguez and Heriberto Rodríguez-Martínez

Journal Article

\section{Tweet}

N.B.: When citing this work, cite the original article.

Original Publication:

Alejandro Vicente-Carrillo, Manuel Álvarez-Rodríguez and Heriberto Rodríguez-Martínez, The CatSper channel modulates boar sperm motility during capacitation., Reproductive biology, 2017.

http://dx.doi.org/10.1016/j.repbio.2017.01.001

Copyright: Elsevier Science B.V., Amsterdam

http://www.elsevier.com/

Postprint available at: Linköping University Electronic Press

http://urn.kb.se/resolve?urn=urn:nbn:se:liu:diva-134398

(c)

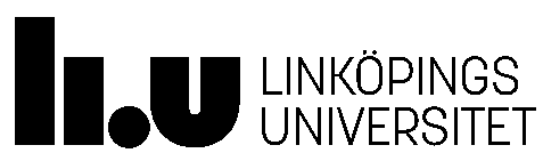




\section{The CatSper channel modulates boar sperm motility during capacitation}

Alejandro Vicente-Carrillo ${ }^{1}$, Manuel Álvarez-Rodríguez ${ }^{1}$, Heriberto Rodríguez-Martínez ${ }^{1 *}$

${ }^{1}$ Department of Clinical and Experimental Medicine, Linköping University, Linköping, Sweden

* Corresponding author: Heriberto Rodríguez-Martínez, Department of Clinical and Experimental Medicine (IKE), Clinical Sciences/O\&G (Campus US, Lab 1, Plan 12), Linköping University, SE-581 85 Linköping, Sweden. E-mail: heriberto.rodríguezmartínez@liu.se. Phone: +46-(0)10-1032284 alt 013-286925. Fax: +46 (0)101034789. http://www.hu.liu.se/ike/forskare-vid-ike/rodriguez-martinez-heriberto?l=en

\section{Acknowledgements}

The study has been made possible by grants from The Swedish Research council VR, Stockholm (Grant 521-2011-6553), the Research Council FORMAS (Grant 221-2011-512), Stockholm, and FORSS (Forskningsrådet i Sydöstra Sverige, Grant 473121), Sweden. Dr. Karl-Eric Magnusson, Dr. Vesa Loitto and Dr. Rudolf Rigler are acknowledged for valuable comments on the manuscript. 


\section{Abstract}

The cation channel of sperm (CatSper) comprises four transmembrane subunits specifically expressed in human, equine, murine and ovine spermatozoa, apparently implicated in capacitation, hyperactivation and acrosome exocytosis. Western blotting and immunocytochemistry showed hereby that CatSper subunits are also present in boar spermatozoa, primarily over the sperm neck, tail and cytoplasmic droplets; albeit CatSper -1 presented in addition some distribution over the membrane of the acrosome and CatSper -2 and -4 over the membrane of the post-acrosome. The role of the Catsper channel in boar spermatozoa was investigated by extending the spermatozoa in media containing different calcium $\left(\mathrm{Ca}^{2+}\right)$ availability and exposure to the capacitation-trigger bicarbonate, to progesterone or CatSper inhibitors (Mibefradil and NNC 55-0396), separately or sequentially, at physiological and toxicological doses. Extracellular $\mathrm{Ca}^{2+}$ availability, combined with bicarbonate exposure (capacitation-inducing conditions) decreased sperm motility, similarly to when spermatozoa incubated in capacitation-inducing conditions were exposed to Mibefradil and NNC 55-0396. Exposure of these spermatozoa to progesterone did not cause significant changes in sperm motility and nor did it revert its decrease induced by CatSper antagonists. In conclusion, the CatSper channel regulates sperm motility during porcine capacitation-related events in vitro.

Keywords: CatSper, spermatozoa, capacitation, sperm motility, boar 


\section{Introduction}

Following ejaculation into the female pig, the once quiescent cauda epididymal spermatozoa are sequentially exposed to various components of the seminal plasma, notably bicarbonate, which induces activation of sperm motility [1]. Spermatozoa are promptly transported to the oviduct where, after colonizing the sperm reservoirs at the utero-tubal junction (UTJ), they await further release to the site of fertilization of the newly ovulated oocyte/s [2]. The upper tubal fluid changes during this period, presumably in relation to imminent ovulation, with increasing levels of bicarbonate towards the tubal ampulla [3; 4]. Biochemical changes that characterize sperm capacitation [5, 6] occur during sperm transport and prime spermatozoa for the acrosome reaction (AR), which is elicited by contact with the zona pellucida (ZP, rev by [7]). The functional set up of sperm capacitation involves, among others, changes at the plasma membrane (i.e. efflux of cholesterol, increase in membrane fluidity, increased calcium $\left(\mathrm{Ca}^{2+}\right)$ permeability and hyperpolarization) leading to increased intracellular $\mathrm{pH}$ and protein-tyrosine phosphorylation $[8,9]$. Sperm capacitation is activated differently among species; i.e. via albumin and progesterone in human and mouse [10-12], heparin and other glycosaminoglycans in bull $[13,14]$ or bicarbonate $\left(\mathrm{HCO}_{3}{ }^{-}\right)$in pig $[3,15]$. Signaling in vivo is gradual and does not massively affect spermatozoa, but occurs as individually progressing spermatozoa encounter increasing concentrations of these substances in the female genital tract $[4,16]$. Alongside capacitation, spermatozoa also change their pattern of motility from activated to hyperactivated, a change in beating force caused by phosphorylation of sperm tail proteins relevant for sperm separation from the tubal epithelium and to achieve the required propulsive force to penetrate the $\mathrm{ZP}$ [17]. Levels of intracellular $\mathrm{Ca}^{2+}\left(\mathrm{iCa}^{2+}\right)$ increase during capacitation, and are essential for hyperactivation and AR [9, 17-20]. 
This essential influx of $\mathrm{Ca}^{2+}$ for $\mathrm{AR}$ is facilitated by membrane $\mathrm{Ca}^{2+}$ channels such as the Transient Receptor Potential (TRP), voltage-activated $\mathrm{Ca}^{2+}$ channels and the CatSper channel [18, 20-24]. Among all $\mathrm{Ca}^{2+}$ channels present in spermatozoa, membrane CatSper is the main $\mathrm{Ca}^{2+}$ channel [21]. CatSper is a $\mathrm{pH}$-sensitive and voltage-gated $\mathrm{Ca}^{2+}$ channel composed by four main subunit proteins: CatSper 1, 2 [25, 26], 3 and 4 [25]. Experiments performed with KO-mice for CatSper genes indicate that CatSper is required for hyperactivated motility and normal male murine fertility [28]. To date, Catsper expression has been identified in mouse (CatSper 1-4, [25-31], human (CatSper 1-4, [11, 30, 32, 33], equine (CatSper 1; [34]), and recently also in ovine (CatSper 1-4; [35]) spermatozoa. An additional series of accessory subunits $(\beta, \delta, \gamma)$ has also been detected in murine and sea urchin spermatozoa [36-38]. Expression of functional CatSper subunits in other species is of interest because its relevance in other models remains undetermined. Genes encoding CatSper 1-4 have been detected in pig, suggesting they might be functional in this species [39].

In human spermatozoa, CatSper is activated by intracellular alkalinization and also by progesterone [11, 21], the latter via the membrane-enzyme ABHD2 [40]. Both alkalinization and progesterone are thus considered inducers of sperm capacitation, hyperactivation and acrosome exocytosis in human spermatozoa [11]. Mouse spermatozoa are, on the contrary, insensitive to progesterone [21] while in vitro capacitated boar spermatozoa show acrosome exocytosis in response to additional supra-physiological doses of progesterone $[19,41]$. CatSper can be endogenously regulated in human spermatozoa by the production of monoacylglycerols belonging to the endocannabinoid family at the sperm plasmalemma [40]. CatSper could also be blocked in either human [11, 42] or horse spermatozoa [34] by exogenous exposure to two known T-type $\mathrm{Ca}^{2+}$ channel inhibitors: Mibefradil and NNC 550396 [43]. Both compounds have previously been reported to specifically inhibit CatSper in different species [11, 21, 34] and NNC 55-0396 is a derivative of Mibefradil with less 
cytotoxicity [43]. Boar spermatozoa have been validated for toxicity studies using total sperm motility, progressive motility and sperm velocity as phenotypic variables [44]. Whether activation and/or blockade of the CatSper channel can be experimentally used for toxicological studies ought to be explored. As evidence suggests, inhibitors of L-type Ca ${ }^{2+}$ channels such as amlodipine, nifedipine or verapamil caused a dose-response reduction of boar sperm motility [44].

Therefore, this study aimed to identify whether CatSper 1, 2, 3 and 4 subunits were functional in ejaculated boar spermatozoa extended in media containing different $\mathrm{Ca}^{2+}$ availability, when exposed to capacitation-trigger bicarbonate, to progesterone or when challenged by CatSper inhibitors (Mibefradil and NNC 55-0396) at physiological and toxicological doses separately or sequentially. Selected preliminary results have been published elsewhere [45].

\section{Material and methods}

\subsection{Experimental design}

Ejaculates collected from fertile breeding boars were primarily extended in either BeltsvilleThawing Solution (BTS, IMV-Technologies, L’Aigle, France) or Durasperm (Jørgen Kruuse A/S, Langeskov, Danmark), pooling three different males to build commercial Artificial Insemination (AI)-doses. Each AI-dose, with a final suspension of $48 \times 10^{6}$ spermatozoa / $\mathrm{mL}$, in a total volume of $80 \mathrm{~mL}$, was transported to the laboratory at $16-20{ }^{\circ} \mathrm{C}$ overnight. Once in the laboratory, the extended sperm suspensions were allotted to the following experiments (Supplementary Figure S1): 
Experiment 1: examined for presence and distribution of CatSper-1, $-2,-3$ and -4 using Western Blotting (WB) and immunocytochemistry (ICC);

Experiment 2: challenged, in non-capacitating medium (BTS) by (i) $\mathrm{NaHCO}_{3}$ (35 mM), or by different concentrations of (ii) progesterone, (iii) Mibefradil or (iv) NNC 55-0396 to determine effective concentrations that have no deleterious effect in spermatozoa;

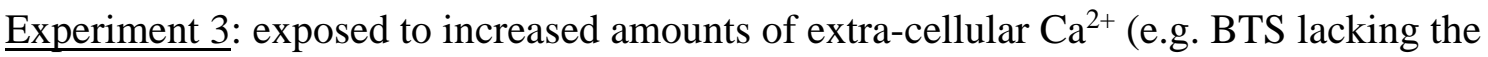
$\mathrm{Ca}^{2+}$-chelator ethylene diamine tetra acetic acid, EDTA) and further subjected to capacitating conditions (35 mM effective extracellular concentration of sodium bicarbonate $\left(\mathrm{NaHCO}_{3}\right)$, capacitation-inducing medium);

Experiment 4: examined for presence of the protein ABHD2, using WB.

Experiment 5: challenged, after incubation in capacitation-inducing medium (BTS without EDTA + 35 mM $\mathrm{NaHCO}_{3}$ ) for 30 min, to progesterone;

Experiment 6: challenged, after incubation in capacitation-inducing medium for $15 \mathrm{~min}$, in two steps; firstly to either Mibefradil or NNC 55-0396 for 15 min and thereafter to progesterone.

Sperm motility (Qualisperm ${ }^{\mathrm{TM}}$ software, Biophos SA, Lausanne, Switzerland), and destabilization/intactness of plasma membrane, acrosome and mitochondria (using flowcytometry (FC) after staining with Propidium Iodide, Annexin V, Lectin-PNA and MitoTracker) were used as phenotypic end-points (Exp 2, 4-6). In addition, concentrations of extracellular $\mathrm{Ca}^{2+}\left(\mathrm{eCa}^{2+}\right)$ of $0.51 \pm 0.13 \mathrm{mM}$ (mean $\pm \mathrm{SEM}$ ) were measured in semen doses 
extended in non-capacitating medium with the Calcium Colorimetric Assay (BioVision, San Francisco, CA, USA) according to the manufacturer's instructions. Intracellular $\mathrm{Ca}^{2+}\left(\mathrm{iCa}^{2+}\right)$ variations were determined in spermatozoa using FC after loading of Fluo-3AM.

All experiments were performed three times with independent samples (independent semen samples from different ejaculates from different males).

\subsection{Animals and sperm collection}

Spermatozoa were obtained from Swedish Hampshire breeding boars, selected according to normal semen quality and proven fertility, supplying semen doses forAI. The boars were kept in individual boxes with straw bedding at Quality Genetics (now Svenska Köttföretagen, SvKF, Hållsta, Sweden), fed with commercial feedstuff (Lantmännen, Stockholm, Sweden) according to national standards [46], provided with water ad libitum and receiving the same management. Semen was manually collected (gloved-hand method) weekly, and the spermrich fraction of the ejaculate from three randomly-selected boars was pooled and extended to a concentration of $48 \times 10^{6}$ spermatozoa / mL. Only ejaculates with a minimum of $70 \%$ motile and 75\% morphologically normal spermatozoa immediately after collection were used to build AI-doses. These doses were cooled down to $16-20{ }^{\circ} \mathrm{C}$ and transported overnight to the laboratory, where they were kept in a Styrofoam box at $18-20^{\circ} \mathrm{C}$ for a maximum of 4 days, during which the experiments were run and sperm motility periodically monitored.

Cauda epididymal murine spermatozoa were used as positive controls for WB and ICC. Spermatozoa were retrieved post-mortem from the caudae epididymides of 6 sexually mature 
black mice used for educational purposes at the Centre for Biomedical Resources (CBR, Linköping University, Sweden). Briefly, the caudae epididymides were dissected with clean scissors and washed in PBS (ThermoFisher Scientific, Waltham, MA, USA) at $37^{\circ} \mathrm{C}$ to remove blood, fat and connective tissue during dissection. Subsequently, clean caudae epididymides were transferred to a clean Petri dish with pre-warmed PBS at $37^{\circ} \mathrm{C}$, the ductus being carefully extruded and sliced. The PBS-collected cauda content was centrifuged at 2,000 x g for 30 seconds to remove remaining tissue debris and blood from the sperm suspension.

All experiments were performed in accordance with relevant regulations (European Community Directive 2010/63/EU) and compliance with current Swedish legislation (SJVFS 2012:26) at the Department of Clinical and Experimental Medicine, Linköping University, Linköping, Sweden. The experimental protocol had previously been reviewed and approved by the Local Ethical Committee for Experimentation with Animals (nr 74-12 for boars and nr 24-15 for mice), Linköping, Sweden.

\subsection{Western blotting (WB)}

Sperm proteins from pig and mouse were extracted after sperm incubation in radio immunoprecipitation assay buffer (RIPA, SIGMA-ALDRICH, Stockholm, Sweden) at $4{ }^{\circ} \mathrm{C}$ for 40 minutes. Samples were thereafter centrifuged $\left(13,000 \mathrm{xg}\right.$ at $4{ }^{\circ} \mathrm{C}$ for $\left.10 \mathrm{~min}\right)$ and the supernatant collected. Protein quantification was performed using the DC Protein assay kit (Bio Rad, USA) according to manufacturer instructions and the protein suspension diluted to a final concentration of $2.5 \mu \mathrm{g} / \mu \mathrm{L}$. Proteins were denatured by heating ( $70{ }^{\circ} \mathrm{C}$ for $10 \mathrm{~min}$ ) and 
10 $\mu$ L-aliquots loaded into a NuPAGE 4-12 \% Bis-Tris SDS-PAGE gel (Life Technologies, USA). Electrophoresis was run at $180 \mathrm{~V}$ at $4{ }^{\circ} \mathrm{C}$ for $90 \mathrm{~min}$, and the proteins were then transferred to polyvinyldifluoride (PVDF) membranes ¿DEBERÍA SER PLURAL, MEMBRANES EN VEZ DE MEMBRANE? (Invitrolon PVDF filter paper sandwich, Life Technologies, Carlsbad, CA, USA) at $125 \mathrm{~mA}$ for $90 \mathrm{~min}$. The membranes were then submerged in $5 \%$ BSA in PBST (PBS (ThermoFisher Scientific, Waltham, MA, USA ) with $0.1 \%$ Tween-20 (SIGMA-ALDRICH, Stockholm, Sweden) for $60 \mathrm{~min}$, washed three times with PBST (5 min) before being incubated with the primary antibodies (1:1,000 for CatSper 1-4 and 1:500 for ABHD2; CatSper 1: rabbit polyclonal antibody to CatSper 1 ab101891; CatSper 2: rabbit polyclonal antibody to CatSper 2 ab101895; CatSper 3: rabbit polyclonal antibody to CatSper 3 ab101894 or CatSper 4: rabbit polyclonal antibody to CatSper 4 ab101892; rabbit polyclonal antibody to ABHD2 ab87157. All antibodies were purchased from Abcam, Cambridge, UK), at $4{ }^{\circ} \mathrm{C}$, overnight. After incubation, the membranes were washed three times in PBST and incubated for 60 min with the secondary antibody (Goat anti rabbit horseradish peroxidase DC03L, Calbiochem, Merck Millipore, Darmstadt, Germany; dilution 1:7,500) followed by extensive washing in PBST. Membranes probed with CatSper 1-4 antibodies were incubated with Super Signal West Pico Chemiluminescent Substrate (Thermo Scientific, Waltham, MA, USA) according to manufacturer instructions and scanned using the C-Digit (LI-COR Biosciences, Lincoln, NE, USA). Images of the blots were obtained using the Image Studio Digits 4.0.21 software (LI-COR Biosciences, Lincoln, NE, USA). For the protein ABHD2, the membranes were washed three times in PBST and incubated for 60 min in a 1:15,000 dilution of the secondary antibody (anti-rabbit IRDye 800 CW, LI-COR Biosciences, Lincoln, NE, USA) followed by extensive washing in PBST. The membranes were scanned using an Odyssey CLx (LI-COR Biosciences, Lincoln, NE, USA) 
and images of the blots were obtained using the Image Studio 4.0 software (LI-COR Biosciences, Lincoln, NE, USA).

\subsection{Immunocytochemistry (ICC)}

Boar and mouse (positive controls) spermatozoa were fixed in $4 \%$ paraformaldehyde at RT for $20 \mathrm{~min}$. The sperm suspensions were then centrifuged (1,200 x g/ $6 \mathrm{~min})$ and the pellet resuspended in Phosphate Buffer Saline (PBS), pH 7.3, to prepare smears on poly-L-lysine slides (LSM, Thermo Scientific, Germany). The smears were allowed to dry, washed three times for 5 min with PBS and blocked with 5\% bovine serum albumin (BSA, SIGMAALDRICH, Stockholm, Sweden) in PBS at $4{ }^{\circ} \mathrm{C}$ for $120 \mathrm{~min}$. After three 5-min washes in PBS, the slides were incubated with the primary antibodies against CatSper 1-4 with 1\% BSA at $4^{\circ} \mathrm{C}$, overnight. The following dilutions were used for boar spermatozoa: 1:25 for CatSper 1, 1:50 for CatSper 2, 1:50 for CatSper 3 and 1:25 for CatSper 4; and 1:25 for all antibodies for murine controls. After incubation, the smears were washed 3 times in PBS for 5 min before incubation with the secondary antibody (polyclonal Goat anti-rabbit Alexa Fluor 568, Molecular Probes, Invitrogen, Carlsbad, CA, USA, diluted 1:1,000 in PBS containing 1\% BSA) at RT for 75 min in darkness and mounted with antifade-reagent Prolong Gold (Molecular Probes, Invitrogen, Carlsbad, CA, USA). The samples were examined under a LSM 700 Zeiss confocal microscope (Carl Zeiss, Sweden) at $630 \mathrm{x}$ using DIC and the images recorded using ZEN Navigator software (Carl Zeiss, Sweden). At least 200 cells were counted in each replicate. 


\subsection{Preparation of the compounds and media}

Stock solutions were prepared before freezing and storage at $-20^{\circ} \mathrm{C}$ until analysis as follows: progesterone (SIGMA-ALDRICH, Stockholm, Sweden) was diluted in ethanol at a concentration of 5 mM; Mibefradil and NNC 55-0396 were diluted in Dimethyl sulfoxide (DMSO, SIGMA-ALDRICH, Stockholm, Sweden) at $30 \mathrm{mM}$ and $10 \mathrm{mM}$ concentrations, respectively. Sodium bicarbonate $\left(\mathrm{NaHCO}_{3}\right.$, SIGMA-ALDRICH, Stockholm, Sweden) was prepared at $70 \mathrm{mM}$ final concentration in BTS with/without EDTA and stored at $4^{\circ} \mathrm{C}$. BTS solutions (BTS without EDTA, BTS with $70 \mathrm{mM} \mathrm{NaHCO3}$ and BTS without EDTA and 70 mM NaHCO3) were monitored for $\mathrm{pH}$ (7.2, 7.9 and 7.9, repectively) and osmolarity (344 mOsm/Kg, $451 \mathrm{mOsm} / \mathrm{Kg}$ and $451 \mathrm{mOsm} / \mathrm{Kg}$ ) after preparation and prior to storage.

\subsection{Sperm exposure to the capacitation trigger bicarbonate, to progesterone, to increased ${ }_{e} \mathrm{Ca}^{2+}$ and to CatSper antagonists (Experiments 2 and 3)}

A sperm suspension was re-extended (1:1, $24 \times 10^{6}$ spermatozoa / mL) in either BTS (Control BTS), modified BTS solutions (BTS without EDTA or BTS without EDTA + bicarbonate, $35 \mathrm{mM}$ ) or BTS with starting concentrations of progesterone (20 $\mu \mathrm{M})$, Mibefradil $(640 \mu \mathrm{M})$ or NNC 55-0396 $(160 \mu \mathrm{M})$ and further diluted to six sequential halfdilutions (in BTS) in $200 \mu \mathrm{L} \mathrm{v/v}$ ratios (total volume: $400 \mu \mathrm{L}$ ). The final tested concentrations were 10, 5, 2.5, 1, 0.1 and $0.01 \mu \mathrm{M}$ for progesterone; 320, 160, 80, 40, 20 and $10 \mu \mathrm{M}$ for Mibefradil; and 80, 40, 20, 10, 5 and $2.5 \mu \mathrm{M}$ for NNC 55-0396. The same v/v ratios were used for control fluids for progesterone (0.2 \% Ethanol in BTS, Control Ethanol), Mibefradil or NNC 55-0396 (1 \% DMSO in BTS, Control DMSO) diluted in BTS at the highest dilution of the tested compound mixed with $200 \mu \mathrm{L}$ of the sperm suspension. Once the spermatozoa were exposed to the different BTS-based media and dilutions of the 
compounds, the samples were placed on a shaking plate inside an incubator at $38{ }^{\circ} \mathrm{C}$ and two sperm aliquots (a $25 \mu \mathrm{L}$ aliquot for FC-analysis and a $10 \mu \mathrm{L}$ aliquot for sperm motility) were taken after 5, 10, 15, 30 and $60 \mathrm{~min}$.

\subsection{Exposure of boar spermatozoa to capacitation-inducing conditions and sequentially to progesterone (Experiment 5)}

Spermatozoa were re-extended 1:1 (to a final concentration of $24 \times 10^{6}$ spermatozoa / mL) in modified BTS without EDTA + $35 \mathrm{mM}$ of $\mathrm{NaHCO}_{3}$ and placed on a shaking plate inside an incubator at $38{ }^{\circ} \mathrm{C}$ for $30 \mathrm{~min}$. Following incubation in capacitation-inducing conditions, the spermatozoa were divided into three aliquots: one that did not receive further treatment, one where $0.01 \mu \mathrm{M}$ progesterone was added and, finally, one where $10 \mu \mathrm{M}$ progesterone was added. After addition of progesterone, re-extended boar spermatozoa were placed on a shaking plate inside an incubator at $38^{\circ} \mathrm{C}$ and a $10 \mu \mathrm{L}$ aliquot of each treatment was taken after 1, 5, 10, 15 and 30 min for motility analyses.

\subsection{Exposure of boar spermatozoa to capacitation-inducing conditions, sequentially to CatSper antagonists followed by progesterone (Experiment 6)}

Spermatozoa were re-extended 1:1 (to a final concentration of $24 \times 10^{6}$ spermatozoa / mL) in modified BTS without EDTA + $35 \mathrm{mM}$ of $\mathrm{NaHCO}_{3}$ and placed on a shaking plate inside an incubator at $38{ }^{\circ} \mathrm{C}$ for $15 \mathrm{~min}$, when a $10 \mu \mathrm{L}$ aliquot was taken for motility analyses and the 
re-extended sperm suspension divided into three aliquots: one that did not receive further treatment, one where $40 \mu \mathrm{M}$ of Mibefradil was added and one where $20 \mu \mathrm{M}$ of NNC 55-0396 was added. After 15 min additional incubation, a $10 \mu \mathrm{L}$ aliquot was taken for motility analyses and the re-extended spermatozoa exposed to Mibefradil and NNC 55-0396 were further divided each one in three aliquots: one where $0.01 \mu \mathrm{M}$ progesterone was added, one where $10 \mu \mathrm{M}$ progesterone was added and, finally, one without any further treatment. After addition of progesterone, re-extended spermatozoa were placed on a shaking plate inside an incubator at $38{ }^{\circ} \mathrm{C}$ and a $10 \mu \mathrm{L}$ aliquot of each treatment was taken after 1 and 5 min for motility analyses.

\subsection{Analysis of membrane stability/intactness, acrosome and mitochondrial integrity and of ${ }_{i} \mathrm{Ca}^{2+}$ via flow cytometry}

Sperm membrane stability/intactness, sperm viability, acrosome integrity and mitochondrial integrity were determined loading spermatozoa with the following fluorophores: Annexin VFITC (Annexin V Apoptosis Detection Kit, BD Pharmingen, San Diego, CA, USA) and Propidium Iodide (PI, Molecular Probes, Invitrogen, Carlsbad, CA, USA), Arachis hypogaea Lectin (AlexaFluor488 (PNA, Molecular Probes, Invitrogen, Carlsbad, CA, USA) and MitoTracker Deep Red (MT, Molecular Probes, Invitrogen, Carlsbad, CA, USA). Changes in ${ }_{i} \mathrm{Ca}^{2+}$ concentration were tracked loading spermatozoa with Fluo-3 AM (Molecular Probes, Invitrogen, Carlsbad, CA, USA) and Propidium Iodide (PI, Molecular Probes, Invitrogen, Carlsbad, CA, USA). Hoescht 33342 (H33342, SIGMA-ALDRICH, Stockholm, Sweden) was used in all cases to define DNA-containing events and discard debris. Stock solutions of the fluorochromes were prepared in miliQ water at $1 \mathrm{mg} / \mathrm{mL}$ of PNA, $2.4 \mathrm{mM}$ of PI and 8.9 
mM of H33342; and in DMSO at $100 \mu \mathrm{M}$ of MT and 1mM for Fluo-3 AM. Stock solutions were kept at $-20^{\circ} \mathrm{C}$ for PNA, PI, MT and Fluo-3 AM and at $+4{ }^{\circ} \mathrm{C}$ for $\mathrm{H} 33342$ and brought to RT immediately before re-dilution in BTS to its use. For analysis of membrane destabilization (early capacitation signs, AnnV+/PI-), a $25 \mu \mathrm{L}$ sperm suspension aliquot was mixed with $175 \mu \mathrm{L}$ of BTS containing $5 \mu \mathrm{L}$ of Annexin V-FITC, $5 \mu \mathrm{L}$ of PI and $4.5 \mu \mathrm{M}$ of H33342. For the variables sperm viability (PNA-/PI-), damaged acrosomes (PNA+/PI+) and mitochondrial integrity (MT+/PI-) a $25 \mu \mathrm{L}$ sperm suspension aliquot was mixed with $175 \mu \mathrm{L}$ of BTS containing $1 \mu \mathrm{g} / \mathrm{mL}$ of PNA, $2.4 \mu \mathrm{M}$ of PI, $100 \mathrm{nM}$ of MT and $4.5 \mu \mathrm{M}$ of H33342. Finally, for $\mathrm{iCa}^{2+}$ concentration, a $25 \mu \mathrm{L}$ sperm suspension aliquot was mixed with $175 \mu \mathrm{L}$ of BTS containing $12 \mu \mathrm{M}$ PI, $1 \mu \mathrm{M}$ Fluo-3 AM and $4.5 \mu \mathrm{M}$ of H33342. The FC-examinations were carried out using a Gallios ${ }^{\mathrm{TM}}$ (Beckman Coulter, Bromma, Sweden) instrument equipped with standards optics, violet laser (405 nm) 2 colours, argon laser (488 nm) 5 colours and HeNe-laser (633 nm) 3 colours. Filter configuration: Blue: FL1 550SP 525BP (PNA, Fluo-3), FL2 595SP 575BP, FL3 655SP 620/30 (PI), FL4 730SP 695/30 - alt 675BP, FL5 755LP; Red: FL6 710SP 660BP (MT), FL7 750SP 725/20, FL8 755LP; Violet: FL9 480SP 450/50 (H33342), FL10 550/40. The instrument is controlled with Navios software (Beckman Coulter, Bromma, Sweden). Analyses of acquired data were performed using the Kaluza software (Beckman Coulter, Bromma, Sweden) on a separate PC. In all cases we assessed 25,000 events per sample, with a flow rate of 500 cells/sec.

\subsection{Sperm motility}

Sperm suspension aliquots ( $24 \times 10^{4}$ spermatozoa in10 $\left.\mu \mathrm{L}\right)$ were placed on a pre-warmed Menzel-Gläser pre-cleaned microscope slide (ThermoFisher Scientific, Waltham, MA, USA. 
Size 76 x $26 \mathrm{~mm}$ ) covered by a pre-warmed coverslip (Size 18 x 18 mm, Thickness number 1, VWR, Stockholm, Sweden). The prepared sample was examined with an upright Zeiss Axio Scope A1 light microscope using a 10 x phase contrast objective (Carl Zeiss, Stockholm, Sweden) equipped with a thermal plate (Temp Controller 2000-2, Pecon GmbH, Erbach, Germany) kept at $38{ }^{\circ} \mathrm{C}$. The microscope was equipped with a Complementary Metal Oxide Silicon (CMOS) camera (UEye, IDS Imaging Development Systems GmbH, Ubersulm, Germany) connected to a personal computer. Sperm motility was assessed using the Qualisperm ${ }^{\mathrm{TM}}$ software (Biophos SA, Lausanne, Switzerland). The Qualisperm ${ }^{\mathrm{TM}}$ technology is based on fluorescence correlation spectroscopy analysis of single particles (spermatozoa) in confocal volume elements, yielding a regression fluctuation algorithm. Individual spermatozoa are projected on a pixel grid of the CMOS camera and the algorithm calculates the number of fluctuations in each pixel by correlation function of sperm numbers and translation classes. Speed distribution and linearity are then determined from the correlation function. This system benefits from a high throughput (usually 4 fields per minute with an acquisition frame rate of 22.6 frames per second, 105 recorded images in a total of 18 ms of exposure time), analyzing $>2,000$ spermatozoa/field and has been validated for several species, including porcine [47-52].

\subsection{Statistics}

All results obtained by exposure to modified BTS-extenders, bicarbonate and progesterone triggers and CatSper inhibitors were tested for normality with the Shapiro-Wilk test and analyzed using IBM SPSS Statistics 23 (IBM Corporation, Armonk, NY, USA) by One-way ANOVA to compare the effect of the different concentrations (dose-response analysis) and 
by repeated ANOVA measurements to compare the different incubation times (time-effect analysis). The post hoc test of Bonferroni was applied to determine whether differences observed were significant at $\mathrm{p}<0.05)$.

\section{Results}

\subsection{Pig spermatozoa expressed CatSper subunits 1, 2, 3 and 4 (Experiment 1)}

Figure 1 a-c summarizes the WB findings for boar and the positive murine control. In pig, there was a band of $50 \mathrm{KDa}$ for CatSper 1, two bands of 50 and $40 \mathrm{KDa}$ for CatSper 2, three bands of 38, 29 and 19 KDa for CatSper 3 and a band of 39 KDa for CatSper 4.

Examination of the ICC slides confirmed that all CatSper subunits were present in murine spermatozoa (positive control, Fig 1 g-j). Negative controls where incubation with the primary antibody was omitted are shown in Figure 1 e-f. Immunolabelling was obvious for all CatSper subunits in $>90 \%$ of ejaculated, BTS-extended, porcine spermatozoa. All four main CatSper subunits were primarily localized over the sperm neck, tail and in cytoplasmic droplets. In addition, CatSper -1 presented some distribution over the membrane of the acrosome and CatSper -2 and -4 over the post-acrosome membrane domain (Fig 2).

3.2. Bicarbonate, progesterone or CatSper inhibitors (Mibefradil or NNC 55-0396) at nontoxic concentrations did not alter sperm motility in boar spermatozoa extended in noncapacitating medium (Experiment 2)

\subsubsection{Sodium bicarbonate}


Increasing the amount of the capacitation trigger sodium bicarbonate in a conventional BTSextender for up to 60 min did not affect sperm motility or membrane stability compared to the controls (Supplementary Table 1).

\subsubsection{Progesterone}

Exposure to different concentrations of progesterone did not significantly modify acrosome integrity or sperm motility compared to the controls. However, sperm viability decreased significantly $(\mathrm{p}<0.05)$ at 30 min incubation for $5 \mu \mathrm{M}$ compared with the Ethanol control but not with the BTS control (Supplementary Table 2).

\subsubsection{Mibefradil}

The two highest tested concentrations of Mibefradil (160 and $320 \mu \mathrm{M})$ significantly $(\mathrm{p}<$ 0.05) reduced sperm viability, increased the number of spermatozoa displaying acrosome exocytosis and abolished sperm motility at all time points of incubation, probably due to a toxic effect of Mibefradil at this concentration. Mibefradil at $80 \mu \mathrm{M}$ also significantly $(\mathrm{p}<$ 0.05) reduced sperm viability, increased the amounts of spermatozoa displaying acrosome exocytosis and abolished sperm motility but only after 60 min incubation (Supplementary Table 3). Mibefradil concentrations of $40 \mu \mathrm{M}$ and lower did not cause any significant reduction in sperm viability at any of the tested time points (Supplementary Table 3).

\subsubsection{NNC 55-0396}


The highest tested concentration of NNC 55-0396 (80 $\mu \mathrm{M})$ significantly $(\mathrm{p}<0.05)$ reduced all studied variables but increased the proportion of spermatozoa displaying acrosome exocytosis at every time-point, probably due to a toxic effect of NNC 55-0396 at this concentration (Supplementary Table 4). In addition, $40 \mu \mathrm{M}$ of NNC 55-0396 had a similar deleterious effect $(\mathrm{p}<0.05)$ after 30 or more min (Supplementary Table 4). At $20 \mu \mathrm{M}$ and lower concentrations, NNC 55-0396 was non-toxic neither in dose-response or time-effect evaluations (Supplementary Table 4).

\subsection{Increased ${ }_{e} \mathrm{Ca}^{2+}$ availability, combined with triggering of capacitation decreased sperm viability and motility and increased acrosome exocytosis (Experiment 3)}

As shown already (Results Experiment 2), exposure to bicarbonate at a capacitating dose (35 $\mathrm{mM} \mathrm{NaHCO} 3$ ) did not affect any of the studied variables (Supplementary Table 1). Increasing the availability of $\mathrm{e}^{2+}$ in the medium did not cause significant changes compared to the control, but combining these procedures led to decreased $(\mathrm{p}<0.05)$ sperm motility compared to the control and to a steady decrease $(\mathrm{p}<0.05)$ in sperm viability, intact mitochondria and increased numbers of spermatozoa displaying acrosome exocytosis (Supplementary Table 5). In addition, increasing $\mathrm{eCa}^{2+}$ availability and bicarbonate (35 mM) increased $\mathrm{iCa}^{2+}$ after 15 min incubation (Supplementary Figure S2).

\subsection{The ABHD2 enzyme was present in boar spermatozoa (Experiment 4)}


The membrane enzyme ABHD2 displayed three bands of approximately 42, 39 and 35 KDa in boar spermatozoa (Figure 3). The positive control (mouse spermatozoa, Figure 3) was confirmatory.

\subsection{Exposure of boar spermatozoa extended in capacitation-inducing medium to progesterone did not modify sperm motility or ${ }_{i} \mathrm{Ca}^{2+}$ concentration (Experiment 5)}

Exposure of boar spermatozoa extended in capacitation-inducing medium (incubated for 30 min) to progesterone at physiological $(0.01 \mu \mathrm{M})$ or pharmacological $(10 \mu \mathrm{M})$ doses did not cause any significant differences in total or progressive sperm motility, compared to when spermatozoa were solely exposed to capacitating-inducing conditions, at any of the studied time points (Supplementary Table 6). In addition, sperm exposure (in control or after incubation with bicarbonate) to progesterone did not modify ${ }_{i} \mathrm{Ca}^{2+}$ (Supplementary Figure S3).

\subsection{Exposure of boar spermatozoa extended in capacitation-inducing medium to CatSper antagonists reduced sperm motility, and further addition of progesterone did not revert previous inhibition (Experiment 6)}

Addition of $40 \mu \mathrm{M}$ of Mibefradil or $20 \mu \mathrm{M}$ NNC 55-0396 to spermatozoa previously extended in capacitation-inducing medium caused a significant $(\mathrm{p}<0.05)$ decrease in sperm motility after 15 min incubation (Figures 4 and 5). This decrease was not reverted by the 
addition of progesterone at physiological $(0.01 \mu \mathrm{M})$ or pharmacological $(10 \mu \mathrm{M})$ doses at any of the studied time points (Figures 4 and 5).

\section{Discussion}

The CatSper is the main $\mathrm{Ca}^{2+}$ channel of human and murine spermatozoa [11, 21], involved in sperm hyperactivation and acrosome exocytosis [11, 21, 25-28]. In the present study, we demonstrated that the CatSper channel is functionally present in ejaculated, extended boar spermatozoa, being implicated in the regulation of sperm motility during capacitation. As expected, bicarbonate did not increase sperm motility in extended, ejaculated spermatozoa [53]. Increases in $\mathrm{eCa}^{2+}$ availability combined with the triggering of capacitation by bicarbonate, increased ${ }_{\mathrm{i}} \mathrm{Ca}^{2+}$ and lowered sperm motility similarly to the display of cells extended in capacitation-inducing medium exposed to $\mathrm{Ca}^{2+}$-channel inhibitors; an effect not potentiated nor modified by the addition of progesterone at different doses, although progesterone acts as CatSper agonist in human spermatozoa [21].

Boar semen for commercial use in AI is usually extended in EDTA-containing extenders to avoid premature changes in sperm motility or spontaneous acrosome exocytosis, events that lead to "sperm infertility” prior to sperm deposition via AI [54, 55]. Consequently, it was priority for this study to determine the $\mathrm{e}^{2+}$ values present in the primary semen extenders, and whether the removal of the $\mathrm{Ca}^{2+}$ chelator caused changes in sperm phenotypic variables and in $\mathrm{iCa}^{2+}$ concentration. Interestingly, only when spermatozoa were exposed to capacitation-inducing conditions (increasing the concentrations of bicarbonate in BTS in the absence of EDTA) the percentage of spermatozoa displaying acrosome exocytosis increased 
significantly, accompanied by a likewise decrease in sperm motility due to a change in sperm movement, depicting small circles caused by an asymmetric beating of the sperm tail.

CatSper subunits 1, 2, 3 and 4 were present in boar spermatozoa, as determined via WB and ICC. The CatSper channel has also been identified in the spermatozoa of human [11, 30, 32, 33], murine [25-29], equine [34] and, very recently even in the ovine species [35]. Notably, the above studies differed in methodology. CatSper 1 (in human, [11]; and in equine, [34]) and CatSper 2 (in human, [32]; and in mouse, [25, 29]) are the only sub-units confirmed by WB, albeit with different antibodies than those used in this study, showing two bands of approximately 90 and 45 KDa for CatSper 1 in human spermatozoa (moreover, the $45 \mathrm{KDa}$ band was argued to be non-specific, [11]), one band of approximately 72 KDa for CatSper 1 in equine spermatozoa [34], one band of approximately 54 KDa for CatSper 2 in human spermatozoa [32] and one band of approximately $67 \mathrm{KDa}$ for CatSper 2 in mouse spermatozoa [25, 29]. The molecular weight of the four main CatSper subunits has also been studied via WB in mouse testis [25, 29, 30, 53]. The approximate obtained molecular weight for the four CatSper subunits in mouse testis was 78KDa for CatSper 1 [56]; $62 \mathrm{KDa}$ [56]) or $67 \mathrm{KDa}[25,25]$ for CatSper 2; $44 \mathrm{KDa}$ [30] or $46 \mathrm{KDa}$ [56]) for CatSper 3; and 43 [56] or 51 KDa [30] for CatSper 4. Overall, and although small variations are possibly due to different SDS-PAGE conditions (see material and methods, [11, 29]) or differences in CatSper-protein homology between species (see below), it seems that the molecular weights obtained for the four CatSper subunits in mouse (positive control) and pig spermatozoa are in agreement with the literature, thus confirming the specificity of the antibodies used here.

In boar spermatozoa, all four CatSper subunits are present over the sperm neck, tail and cytoplasmic droplets. In addition, CatSper -1 presented some distribution over the membrane of the acrosome and CatSper -2 and -4 over the membrane of the post-acosome . The results presented here for mouse (positive control) and pig spermatozoa are in agreement with the 
literature in murine [25-31] equine [34] and human spermatozoa [11], where the CatSper channel has been shown to be present mainly in the membrane of the sperm tail. However, the reported distribution of CatSper subunits in mouse via ICC is inconsistent: CatSper (without specification of which subunit was studied) in the principal piece [26]; CatSper 2: uniformly along the tail [25] or the principal piece [29]; CatSper 3: acrosome [30] or midpiece and cytoplasmic droplet [31]; CatSper 4: acrosome [30] or midpiece and cytoplasmic droplet [31] or principal piece [28]. In addition, in human spermatozoa only CatSper 1 [11] and 2 [32] have been identified via ICC, CatSper 1 being distributed (as can be observed in the figures presented by [11]), over the membrane of the cytoplasmic droplets, midpiece and sperm head, while CatSper 2 was present in the whole sperm tail [32]. Finally, CatSper 1 has been studied in equine spermatozoa, with a distribution restricted to the principal piece [34]. The low degree of homology between species (for instance the human CatSper 1 shares $48.7 \%$ of amino acid sequence identity with mouse and $57.4 \%$ with pig [39], the human CatSper 2 shares $67.6 \%$ with mouse and $79 \%$ with pig [39], the human CatSper 3 shares $66.1 \%$ with mouse and $69.6 \%$ with pig [28, 39], whereas the human CatSper 4 shares $71.8 \%$ with mouse and $74.2 \%$ with pig $[28,39])$ could contribute to explaining the small differences obtained in molecular weights and distribution of the CatSper subunits among species (the antibodies used in this study, for instance, were designed against the human CatSper subunits). The low degree of homology between human and pig CatSper 1 proteins might also explain why CatSper 1 also appeared distributed over the membrane of the acrosome while the other 3 subunits were mostly restricted to the sperm tail. Moreover, CatSper 1 has low homology to CatSper 3 (20 \% identity to CatSper 1, [28] and CatSper 4 (24 \% homology to CatSper 1, [28]), which might also contribute to explaining differences in membrane distribution and molecular weight among CatSper subunits. 
The potential role of the CatSper channel was explored by exposing ejaculated, extended, boar spermatozoa to the capacitation-trigger bicarbonate (35 $\mathrm{mM}$ of $\mathrm{NaHCO}_{3}$ ), to progesterone and to the $\mathrm{Ca}^{2+}$-channel inhibitors Mibefradil and NNC 55-0396. Furthermore, spermatozoa extended in capacitation-inducing medium were challenged by CatSper antagonists and progesterone. Neither the proportions of motile- nor progressive motile spermatozoa were significantly affected by non-toxic treatments of CatSper antagonists when extended in non-capacitating medium. On the other hand, these spermatozoa albeit not affected by progesterone, exhibited a reduction in motility after incubation with CatSper antagonists. Progesterone, via the ABHD2 enzyme [40], activates CatSper in human spermatozoa. Even though the ABHD2 protein is, as shown here, present in the pig spermatozoon, none of the studied variables were significantly affected by exposure to progesterone, irrespective of cells, extended neither in non-capacitation- nor in capacitationinducing media. Thus, progesterone does not appear to activate CatSper in boar, while the CatSper channel is only inhibited by Mibefradil and NNC 55-0396 when pig spermatozoa are exposed to capacitation-inducing media.

In other species such as human [11], equine [34] or mouse [29], CatSper has been implicated in capacitation and attainment of hyperactivated sperm motility. Moreover, sperm CatSper appears activated by progesterone in human [21, 42], probably increasing motility and triggering hyperactivated motility as well as acrosome reaction [57]. However, other studies have questioned whether these eventual effects of progesterone are mediated via CatSper or are dependent on other mechanisms [12]. Boar spermatozoa do not massively capacitate upon exposure to bicarbonate [16] or to the progesterone-containing oviductal fluid [3] despite displaying progesterone membrane receptors [58]. In consequence, it is obvious that exposure to neither bicarbonate nor progesterone appears to be convincingly related to the stimulation of the CatSper in boar spermatozoa, e.g. they are not specific CatSper agonists. 
On the other hand, the $\mathrm{Ca}^{2+}$-channel inhibitors Mibefradil and NNC 55-0396 are defined as CatSper-inhibitors in human [11, 42] and equine [34] and they can abolish human sperm function at concentrations higher than $30 \mu \mathrm{M}$ for Mibefradil and $10 \mu \mathrm{M}$ for NNC 55-0396 [11]. In addition, concentrations higher than $40 \mu \mathrm{M}$ Mibefradil and $10 \mu \mathrm{M}$ for NNC 55-0396 evoke themselves $\mathrm{Ca}^{2+}$ responses in human spermatozoa [42] by causing intracellular alkalinization [22]. NNC 55-0396 completely inhibits human CatSper at concentrations as low at $2 \mu \mathrm{M}$ [21]. In equine spermatozoa, the greatest suppression of $\mathrm{Ca}^{2+}$ fluxes occurs when

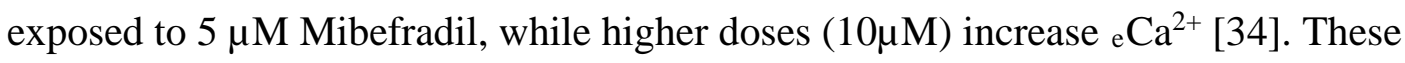
observations are in agreement with the results presented here, where Mibefradil at $40 \mu \mathrm{M}$ or NNC 55-0396 at $20 \mu \mathrm{M}$ partially blocked motility and progressive motility of boar spermatozoa extended in capacitation-inducing medium; while a total blockade (and cell death) occurred at higher concentrations of both CatSper antagonists.

Boar spermatozoa can survive in conventional semen extenders such as BTS for several days, provided storage temperature is kept between 17 and $22{ }^{\circ} \mathrm{C}$ [59]. In the present experiments, where incubation and challenge temperatures mimicked body temperature in pigs $\left(38^{\circ} \mathrm{C}\right)$, sperm viability (including all parameters measured) decreased over time. Such deterioration is known in boar spermatozoa when incubated in control media, particularly for motility variables. However, the intervals used are to be considered relatively shorter compared with comparative studies in human [11] and horse [34]. In the light of the present studies, caution should be taken when incubating small volumes of sperm at body temperature for a long time in simple media, as this can lead to misinterpretation due to alterations in sperm metabolism. When boar spermatozoa abandon the sperm reservoir at the utero-tubal junction (UTJ) and start their journey towards the oocyte, increasing levels of bicarbonate trigger sperm capacitation [3, 4], which is followed by hyperactivation of their motility to escape epithelial binding [7]. Changes in capacitation start in vivo and in vitro by increasing concentrations of 
bicarbonate in the extracellular fluid $[3,15]$ which, as shown here, will allow for the functional activation of CatSper. Interestingly, progesterone, evenly present alongside the entire oviduct wall and intraluminal fluid, does not seem to activate Catsper in boar spermatozoa as it does in human [21]. In human and mouse, rheotaxis (the ability to swim against the flow of surrounding fluids) seems to be the main mechanism by which spermatozoa find their way towards the oocyte [60]. CatSper mouse mutants show a disrupted rheotactic response [61]. The simple mechanical effect of swimming against the intraluminal tubal fluid flow, moving from the ampulla towards the UTJ during the periovulatory period [62], combined with increasing concentrations of bicarbonate in the tubal fluid may, in vivo, produce a washing-effect of the sperm membrane allowing for the activation of available receptors and channels such as CatSper. Such CatSper activation will lead to hyperactivated motility, further enabling spermatozoa to swim through the commonly adjoined expanded cumulus cloud surrounding the oocytes. In such in vivo conditions, the CatSper channel would only be functional in capacitated spermatozoa, a picture that corresponds well with the present in vitro observations.

In conclusion, CatSper subunits 1, 2, 3 and 4 are present in ejaculated, extended, boar spermatozoa. Neither bicarbonate nor progesterone appear to act as specific CatSper agonists while Mibefradil and NNC 55-0396 effectively blocked CatSper acting as specific antagonists in boar spermatozoa exposed to capacitation-inducing media.

\section{Conflict of interest}

The authors declare no conflict of interest. 


\section{Author Contribution}

A.V.C. performed the experiments and wrote the first draft of the manuscript. M.A.R. assisted with the experiments and draft writing. H.R.M. designed the experiment, supervised the work and corrected the manuscript. All authors approved the final version of the manuscript. 


\section{References}

[1] Rodríguez-Martinez, H. Aspects of the electrolytic composition of boar epididymal fluid with reference to sperm maturation and storage. Reprod Domest Anim. 1991; Suppl 1:13-27.

[2] Rodríguez-Martínez H, Saravia F, Wallgren M, Tienthai P, Johannisson A, Vázquez JM, Martínez E, Roca J, Sanz L, Calvete JJ. Boar spermatozoa in the oviduct. Theriogenology. 2005; 63:514-535.

[3] Tienthai P, Johannisson A, Rodriguez-Martinez H. Sperm capacitation in the porcine oviduct. Anim Reprod Sci. 2004; 80:131-146.

[4] Rodriguez-Martinez H. Role of the oviduct in sperm capacitation. Theriogenology. 2007; 68 Suppl 1:S138-146.

[5] Austin CR. Observations on the penetration of the sperm in the mammalian egg. Aust $\mathrm{J}$ Sci Res B. 1951; 4:581-596.

[6] Chang MC. Fertilizing capacity of spermatozoa deposited into the fallopian tubes. Nature. 1951; 168:697-698.

[7] Gadella BM, Luna C. Cell biology and functional dynamics of the mammalian sperm surface. Theriogenology. 2014; 81:74-84.

[8] Ickowicz D, Finkelstein M, Breitbart H. Mechanism of sperm capacitation and the acrosome reaction: role of protein kinases. Asian J Androl. 2012; 14:816-821.

[9] Gadella BM, Boerke A. 2016. An update on post-ejaculatory remodeling of the sperm surface before mammalian fertilization. Theriogenology 85:113-124.

[10] Xia J, Ren D. The BSA-induced Ca2+ influx during sperm capacitation is CATSPER channel-dependent. Reprod Biol Endocrinol. 2009; 7:119.

[11] Tamburrino L, Marchiani S, Minetti F, Forti G, Muratori M, Baldi E. The CatSper calcium channel in human sperm: relation with motility and involvement in progesteroneinduced acrosome reaction. Hum Reprod. 2014; 29:418-428.

[12] Uñates D, Guidobaldi H, Gatica L, Cubilla M, Teves M, Moreno A, Giojalas LC. Versatile Action of Picomolar Gradients of Progesterone on Different Sperm Subpopulations. Plos One. 2014; 9:e91181.

[13] Parrish JJ, Susko-Parrish J, Winer MA, First NL. Capacitation of bovine sperm by heparin. Biol Reprod. 1988; 38:1171-1180.

[14] Bergqvist A-S, Ballester J, Johannisson A, Lundeheim N, Rodríguez-Martínez H. Heparin and dermatan sulphate induced capacitation of frozen-thawed bull spermatozoa measured by merocyanine-540. Zygote. 2007; 15:225-232. 
[15] Harrison R, Gadella B. Bicarbonate-induced membrane processing in sperm capacitation. Theriogenology. 2005; 63:342-351.

[16] Saravia F, Hernández M, Wallgren MK, Johannisson A and Rodríguez-Martínez H. Cooling during semen cryopreservation does not induce capacitation of boar spermatozoa. Int J Androl. 2007; 30:485-499.

[17] Suarez S. Control of hyperactivation in sperm. Hum Reprod Update. 2008; 14:647-657.

[18] Alasmari W, Costello S, Correia J, Oxenham SK, Morris J, Fernandes L, RamalhoSantos J, Kirkman-Brown J, Michelangeli F, Publicover S, Barratt CL. Ca2+ signalling through CatSper and $\mathrm{Ca} 2+$ stores regulate different behaviours in human sperm. J Biol Chem. 2013; 288:6248-6258.

[19] Yeste M, Fernández-Novell JM, Ramió-Lluch L, Estrada E, Rocha LG, Cebrián-Pérez JA, Muiño-Blanco T, Concha II, Ramírez A, Rodríguez-Gil JE. Intracellular calcium movements of boar spermatozoa during 'in vitro' capacitation and subsequent acrosome exocytosis follow a multiple-storage place, extracellular calcium-dependent model. Andrology. 2015; 3:729-747.

[20] Correia J, Michelangeli F, Publicover S. Regulation and roles of Ca2+ stores in human sperm. Reproduction. 2015; 150:R65-76.

[21] Lishko PV, Botchkina IL, Kirichok Y. Progesterone activates the principal Ca2+ channel of human sperm. Nature. 2011; 471:387-391.

[22] Brenker C, Goodwin N, Weyand I, Kashikar ND, Naruse M, Krähling M, Müller A, Kaupp UB, Strünker T. The CatSper channel: a polymodal chemosensor in human sperm. EMBO J. 2012; 31:1654-1665.

[23] Kwon WS, Park YJ, Mohamed el-SA, Pang MG. Voltage-dependent anion channels are a key factor of male fertility. Fertil Steril. 2013; 99:354-361.

[24] Rahman MS, Kwon WS, Pang MG. Calcium influx and male fertility in the context of the sperm proteome: an update. Biomed Res Int. 2014; 2014:841615.

[25] Quill TA, Ren D, Clapham DE, Garbers DL. A voltage-gated ion channel expressed specifically in spermatozoa. Proc Natl Acad Sci U S A. 2001; 98:12527-12531.

[26] Ren D, Navarro B, Perez G, Jackson AC, Hsu S, Shi Q, Tilly JL, Clapham DE. A sperm ion channel required for sperm motility and male fertility. Nature. 2001; 413:603-609.

[27] Lobley A, Pierron V, Reynolds L, Allen L, Michalovich D. Identification of human and mouse CatSper3 and CatSper4 genes: characterisation of a common interaction domain and evidence for expression in testis. Reprod Biol Endocrinol. 2003; 1:53.

[28] Qi H, Moran MM, Navarro B, Chong JA, Krapivinsky G, Krapivinsky L, Kirichok Y, Ramsey IS, Quill TA, Clapham DE. All four CatSper ion channel proteins are required for 
male fertility and sperm cell hyperactivated motility. Proc Natl Acad Sci U S A. 2007; 104:1219-1223.

[29] Quill TA, Sugden SA, Rossi KL, Doolittle LK, Hammer RE, Garbers D. Hyperactivated sperm motility driven by CatSper2 is required for fertilization. Proc Natl Acad Sci U S A. 2003; 100:14869-14874.

[30] Jin JL, O'Doherty AM, Wang S, Zheng H, Sanders KM, Yan W. Catsper3 and catsper4 encode two cation channel-like proteins exclusively expressed in the testis. Biol Reprod. 2005; 73:1235-1242.

[31] Jin J, Jin N, Zheng H, Ro S, Tafolla D, Sanders KM, Yan W. Catsper3 and Catsper4 are essential for sperm hyperactivated motility and male fertility in the mouse. Biol Reprod. 2007; 77:37-44.

[32] Bhilawadikar R, Zaveri K, Mukadam L, Naik S, Kamble K, Modi D, Hinduja I. Levels of Tektin 2 and CatSper 2 in normozoospermic and oligoasthenozoospermic men and its association with motility, fertilization rate, embryo quality and pregnancy rate. J Assist Reprod Genet. 2013; 30:513-523.

[33] Smith JF, Syritsyna O, Fellous M, Serres C, Mannowetz N, Kirichok Y, Lishko PV. Disruption of the principal, progesterone-activated sperm Ca2+ channel in a CatSper2-deficient infertile patient. Proc Natl Acad Sci U S A. 2013; 110:6823-6828.

[34] Loux SC, Crawford KR, Ing NH, González-Fernández L, Macías-García B, Love CC, Varner DD, Velez IC, Choi YH, Hinrichs K. CatSper and the relationship of hyperactivated motility to intracellular calcium and pH kinetics in equine sperm. Biol Reprod. 2013; 89:123.

[35] Vicente-Carrillo A, Casao A, Pérez-Pé R, Cebrián-Pérez JA, Muiño-Blanco MT, Rodríguez-Martínez H. Membrane receptor mapping in ejaculated ram spermatozoa. Reprod Domest Anim. 2015; 50S3: P-153:81-82.

[36] Liu J, Xia J, Cho KH, Clapham DE, Ren D. CatSperbeta, a novel transmembrane protein in the CatSper channel complex. J Biol Chem. 2007; 282:18945-18952.

[37] Wang H, Liu J, Cho KH, Ren D. A novel, single, transmembrane protein CATSPERG is associated with CATSPER1 channel protein. Biol Reprod. 2009; 81:539-544.

[38] Seifert R, Flick M, Bönigk W, Alvarez L, Trötschel C, Poetsch A, Müller A, Goodwin N, Pelzer P, Kashikar ND, Kremmer E, Jikeli J, Timmermann B, Kuhl H, Fridman D, Windler F, Kaupp UB, Strünker T. The CatSper channel controls chemosensation in sea urchin sperm. EMBO J. 2015; 34:379-392.

[39] Song C, Gao B, Wu H, Xie Y, Wang X, Li B, Chen G, Mao J. Molecular cloning, spatial and temporal expression analysis of CatSper genes in the Chinese Meishan pigs. Reprod Biol Endocrinol. 2011; 9:132. 
[40] Miller M, Mannowetz N, Iavarone A, Safavi R, Gracheva E, Smith J, Hill R, Bautista D, Kirichok Y, Lishko P. Unconventional endocannabinoid signaling governs sperm activation via sex hormone progesterone. Science. 2016; 352:555-559.

[41] Ramió L, Rivera MM, Ramírez A, Concha II, Peña A, Rigau T, Rodríguez-Gil JE. Dynamics of motile-sperm subpopulation structure in boar ejaculates subjected to 'in vitro' capacitation and further 'in vitro' acrosome reaction. Theriogenology. 2008; 69:501-512.

[42] Strünker T, Goodwin N, Brenker C, Kashikar ND, Weyand I, Seifert R, Kaupp UB. The CatSper channel mediates progesterone-induced Ca2+ influx in human sperm. Nature. 2011; 471:382-386.

[43] Bui PH, Quesada A, Handforth A, Hankinson O. The Mibefradil derivative NNC550396, a specific T-type calcium channel antagonist, exhibits less CYP3A4 inhibition than Mibefradil. Drug Metab Dispos. 2008; 36:1291-1299.

[44] Vicente-Carrillo A, Edebert I, Garside E, Cotgreave I, Rigler R, Loitto V, Magnusson KE, Rodríguez-Martínez H. Boar spermatozoa successfully predict mitochondrial modes of toxicity: Implications for drug toxicity testing and the 3R principles. Toxicol in Vitro. 2015; 29:582-591.

[45] Vicente-Carrillo A, Loitto V, Magnusson KE, Rigler R and Rodríguez-Martínez H. The CatSper receptor family is present in boar spermatozoa. Reprod Domest Anim. 2014; 49S3: P194-99.

[46] Simonsson, A. Näringsrekommendationer och fodermedelstabeller till svin [Nutrient and metabolizable energy recommendations for swine, in Swedish]. Swedish University of Agricultural Sciences, SLU. 1994; Info. Rapporter, Husdjur. 75pp.

[47] Tejerina F, Buranaamnuay K, Saravia F, Wallgren M, Rodriguez-Martinez H. Assessment of motility of ejaculated, liquid-stored boar spermatozoa using computerized instruments. Theriogenology. 2008; 69:1129-1138.

[48] Tejerina F, Morrell J, Petterson J, Dalin AM, Rodriguez-Martinez H. Assessment of motility of ejaculated stallion spermatozoa using a novel computer-assisted motility analyzer (Qualisperm ${ }^{\mathrm{TM}}$ ) Animal Reprod. 2009; 6:380-385.

[449] Rodríguez-Martinez H, Saravia F, Wallgren M, Roca J, Peña FJ. Influence of seminal plasma on the kinematics of boar spermatozoa during freezing. Theriogenology. 2008; 70:1242-1250.

[50] Johannisson A, Morrell JM, Thorén J, Jönsson M, Dalin AM, Rodriguez-Martinez H. Colloidal centrifugation with Androcoll-E ${ }^{\mathrm{TM}}$ prolongs stallion sperm motility, viability and chromatin integrity. Anim Reprod Sci. 2009; 116:119-128.

[51] Siqueira AP, Wallgren M, Hossain MS, Johannisson A, Sanz L, Calvete JJ, RodríguezMartínez H. Quality of boar spermatozoa from the sperm-peak portion of the ejaculate after 
simplified freezing in MiniFlatpacks compared to the remaining spermatozoa of the sperm-rich fraction. Theriogenology. 2011; 75:1175-1184.

[52] Vicente-Carrillo A, Álvarez-Rodríguez M, Rodríguez-Martínez H. The mu ( $\mu$ ) and delta $(\delta)$ opioid receptors modulate boar sperm motility. Mol Reprod Dev. 2016; 83:724-734.

[53] Holt WV, Harrison RA. Bicarbonate stimulation of boar sperm motility via a protein kinase A-dependent pathway: between-cell and between-ejaculate differences are not due to deficiencies in protein kinase A activation. J Androl. 2002; 23:557-565.

[54] Matás C1, Coy P, Romar R, Marco M, Gadea J, Ruiz S. Effect of sperm preparation method on in vitro fertilization in pigs. Reproduction. 2003; 125:133-141.

[55] Knox RV. Artificial insemination in pigs today. Theriogenology. 2016; 85:83-93.

[56] Luo T, Zou QX, He YQ, Wang HF, Wang T, Liu M, Chen Y, Wang B. Matrine compromises mouse sperm functions by a $[\mathrm{Ca}(2+)]$ i-related mechanism. Reprod Toxicol. 2016; 60:69-75.

[57] Sagare-Patil V, Galvankar M, Satiya M, Bhandari B, Gupta S, Modi D. Differential concentration and time dependent effects of progesterone on kinase activity, hyperactivation and acrosome reaction in human spermatozoa. Int J Androl. 2012; 35:633-644.

[58] De Amicis F, Santoro M, Guido C, Sisci D, Bruno R, Carpino A, Aquila S. Progesterone through progesterone receptors affects survival and metabolism of pig sperm. Anim Reprod Sci. 2012; 135:75-84.

[59] Pursel VG, Johnson LA, Schulman LL. Effect of dilution, seminal plasma and incubation period on cold shock susceptibility of boar spermatozoa. J Anim Sci. 1973; 37:528-531.

[60] Miki K, Clapham DE. Rheotaxis guides mammalian sperm. Curr Biol. 2013; 23:443452.

[61] Ishimoto K, Gaffney EA. Fluid flow and sperm guidance: a simulation study of hydrodynamic sperm rheotaxis. J R Soc Interface. 2015; pii: 20150172. DOI: 10.1098/rsif.2015.0172.

[62] Rodriguez-Martinez H, Einarsson S, Larsson B. Spontaneous motility of the oviduct in the anaesthetized pig. J Reprod Fert. 1982; 66:615-624. 


\section{Figure Legends}

Figure 1. A-D: Western Blotting images for the CatSper subunits 1, 2, 3 and 4 in mouse (positive control) and pig spermatozoa. A: CatSper 1. B: CatSper 2. C: CatSper 3. D: CatSper 4. E-F: Immunocytochemical controls (primary antibody excluded) in boar (E) and mouse (F) spermatozoa, Confocal laser scanning microscopy, 630 x. Scale bar: $10 \mu \mathrm{m}$. Left: fluorescence, dark field. Right: DIC. G-J: Immunocytochemical localization of CatSper 1 (G), 2 (H), $3(\mathrm{I})$ and $4(\mathrm{~J})$ in murine spermatozoa (positive control).

Figure 2. Immunocytochemical localization of CatSper subunits in boar spermatozoa. The white arrows indicate the distribution of the CatSper subunits over the membrane of the neck, cytoplasmic droplets and tail. Confocal images are shown on the left side and DIC images on the right side. A) CatSper -1: distributed over the membrane of the neck, tail, cytoplasmic droplets (proximal or distal) and acrosome. B) CatSper -2: distributed over the membrane of the neck and principal piece with a lower staining over the membrane of the post-acrosome. C) CatSper-3: distributed over the membrane of the sperm neck, the principal piece of the tail and on cytoplasmic droplets. D) CatSper-4: distributed over the membrane of the neck, the sperm tail and the post-acrosome domain. Scale bar: $10 \mu \mathrm{m}$.

Figure 3. Western Blotting images for the ABHD2 in mouse (positive control, $30 \mathrm{KDa}$ ) and pig spermatozoa (three size bands 42, 39 and $35 \mathrm{KDa}$ ). 
Figure 4. Motility changes in boar spermatozoa incubated in capacitating medium for 15 min followed by addition of $40 \mu \mathrm{M}$ of the CatSper antagonist Mibefradil and posterior addition of either $0.01 \mu \mathrm{M}$ or $10 \mu \mathrm{M}$ progesterone. CAP: Control Capacitated; Mib: Control Mibefradil; 0.01 P4: $0.01 \mu \mathrm{M}$ of progesterone; $10 \mathrm{P} 4: 10 \mu \mathrm{M}$ of progesterone.

Figure 5. Motility changes in boar spermatozoa incubated in capacitating medium for 15 min followed by addition of $20 \mu \mathrm{M}$ of the CatSper antagonist NNC 55-0396 and posterior addition of either $0.01 \mu \mathrm{M}$ or $10 \mu \mathrm{M}$ progesterone. CAP: Control Capacitated; NNC: Control NNC 55-0396; 0.01 P4: $0.01 \mu \mathrm{M}$ of progesterone; $10 \mathrm{P} 4: 10 \mu \mathrm{M}$ of progesterone.

\section{Supplementary Figures Legends}

Supplementary Figure S1. Flow Chart of the experimental design regarding sperm challenge to different media and compounds.

\section{Supplementary Figure S2. Subpopulations of boar spermatozoa depicting high (H} gating) or low (L gating) ${ }_{\mathrm{i}} \mathrm{Ca}^{2+}$ during capacitation. A: pig spermatozoa extended in BTS incubated for $15 \mathrm{~min}$ at $38{ }^{\circ} \mathrm{C}$ (Control). B: spermatozoa incubated for $15 \mathrm{~min}$ in capacitating medium (BTS without EDTA + $35 \mathrm{mM}$ of $\mathrm{NaHCO}_{3}$ ) at $38^{\circ} \mathrm{C}$. C: spermatozoa extended in BTS incubated for $30 \mathrm{~min}$ at $38{ }^{\circ} \mathrm{C}$ (Control). D: spermatozoa incubated for $30 \mathrm{~min}$ in capacitating medium at $38^{\circ} \mathrm{C}$. 


\section{Supplementary Figure S3. Subpopulations of boar spermatozoa depicting high (H}

gating) or low ( $\mathrm{L}$ gating) $\mathrm{CCa}^{2+}$ before and after addition of progesterone. A: pig spermatozoa incubated for $31 \mathrm{~min}$ in capacitating medium (BTS without EDTA + $35 \mathrm{mM}$ of $\mathrm{NaHCO}_{3}$ ) at $38{ }^{\circ} \mathrm{C}$. B: spermatozoa incubated for $30 \mathrm{~min}$ in capacitating medium at $38{ }^{\circ} \mathrm{C}, 1$ min after addition of $0.01 \mu \mathrm{M}$ of progesterone. C: spermatozoa incubated for $30 \mathrm{~min}$ in capacitating medium at $38{ }^{\circ} \mathrm{C}, 1 \mathrm{~min}$ after addition of $10 \mu \mathrm{M}$ of progesterone. D: spermatozoa incubated for $35 \mathrm{~min}$ in capacitating medium at $38^{\circ} \mathrm{C}$. E: spermatozoa incubated for $30 \mathrm{~min}$ in capacitating medium at $38^{\circ} \mathrm{C}, 5$ min after addition of $0.01 \mu \mathrm{M}$ of progesterone. $\mathrm{F}$ : spermatozoa incubated for $30 \mathrm{~min}$ in capacitating medium at $38^{\circ} \mathrm{C}, 5 \mathrm{~min}$ after addition of 10 $\mu \mathrm{M}$ of progesterone. 
Figure 1
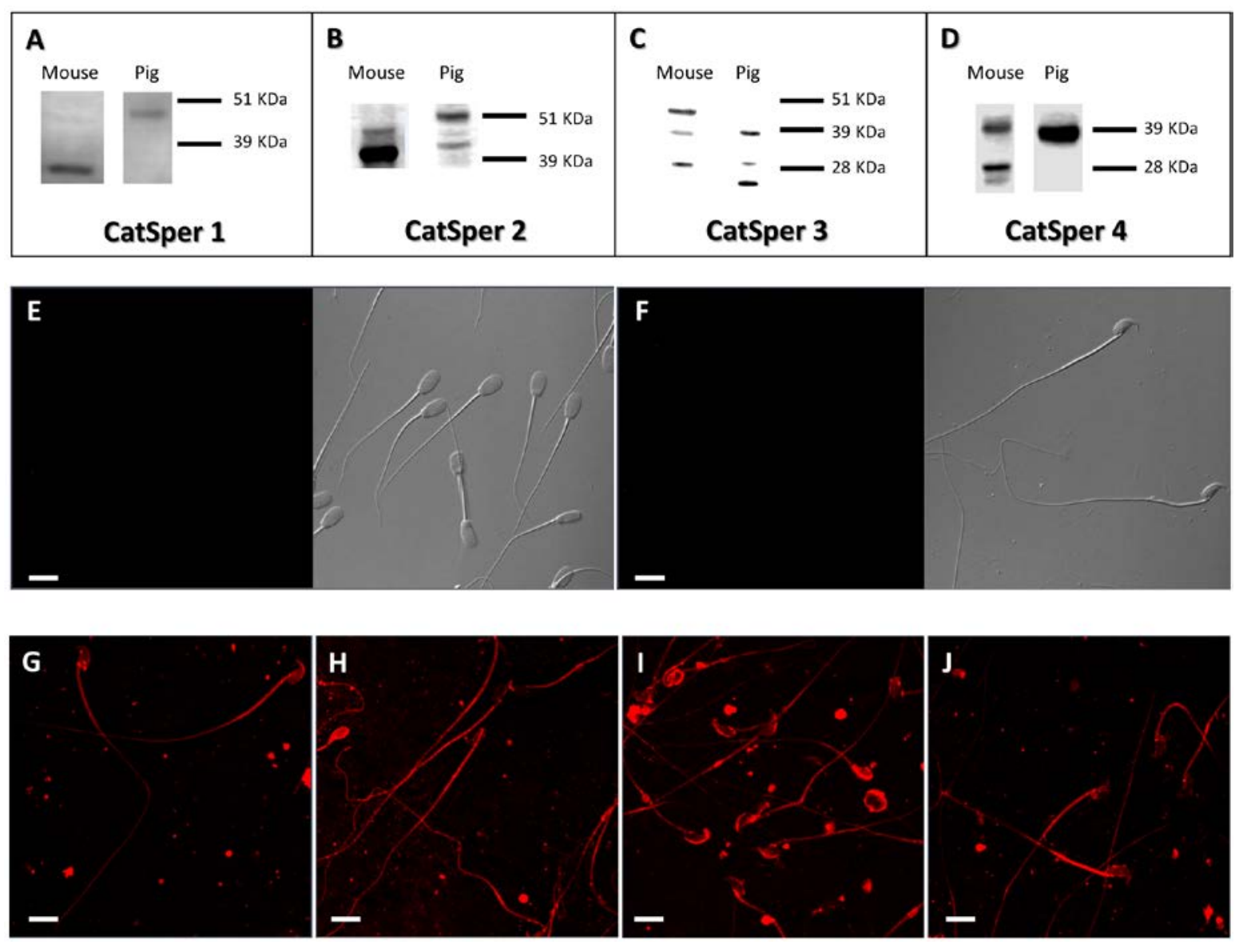
Figure 2
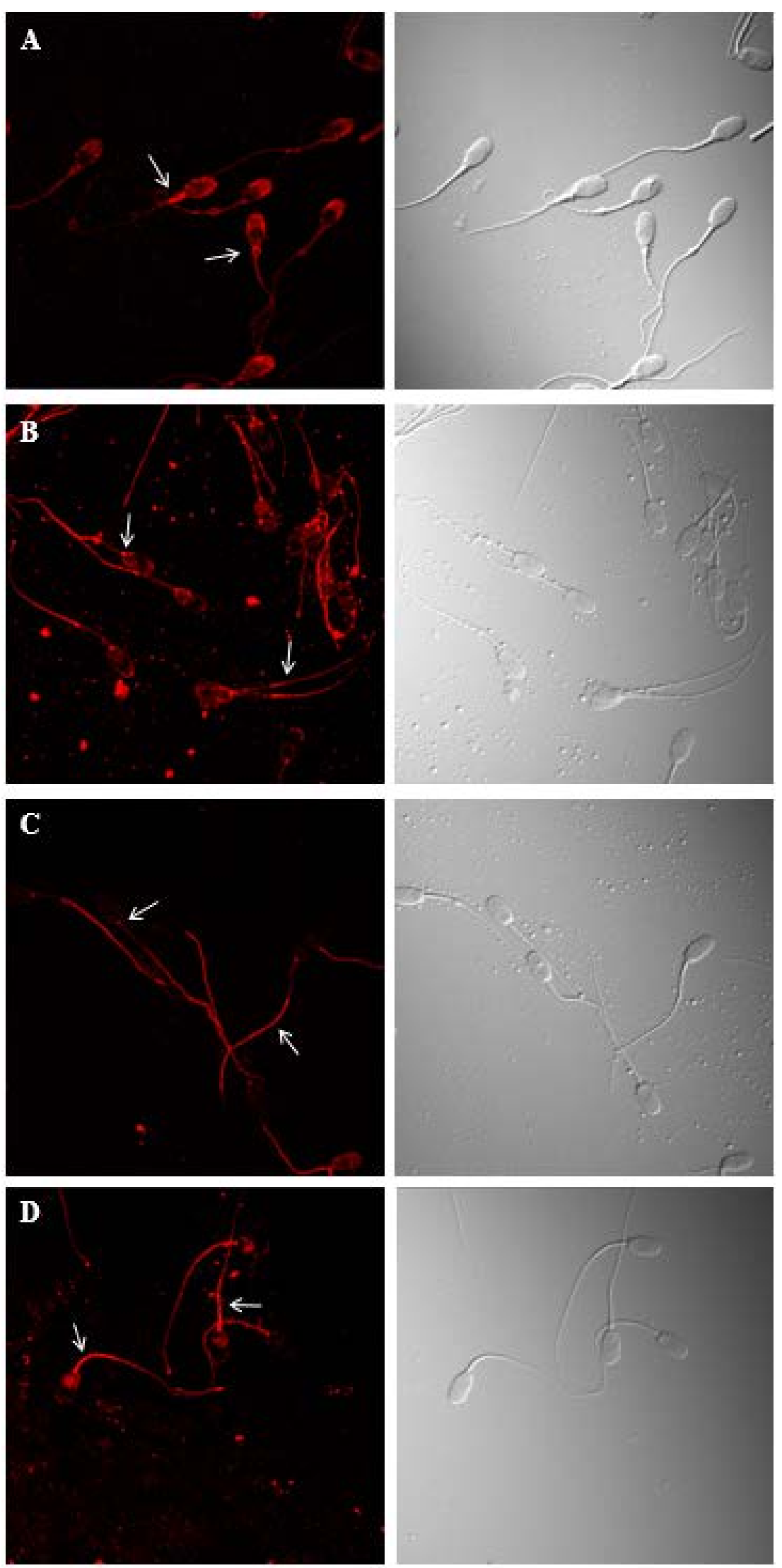
Figure 3

\section{$\mathrm{ABDH} 2$}

Mouse Pig

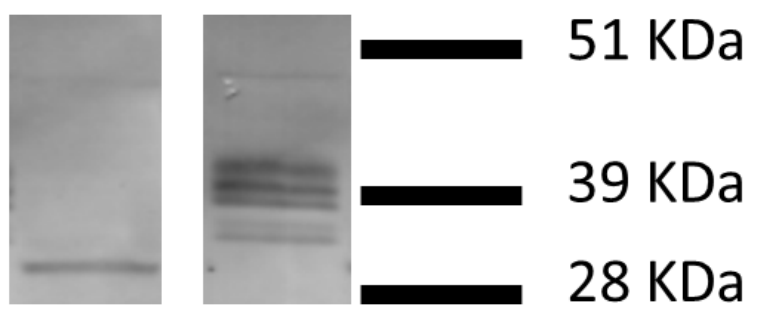


Figure 4
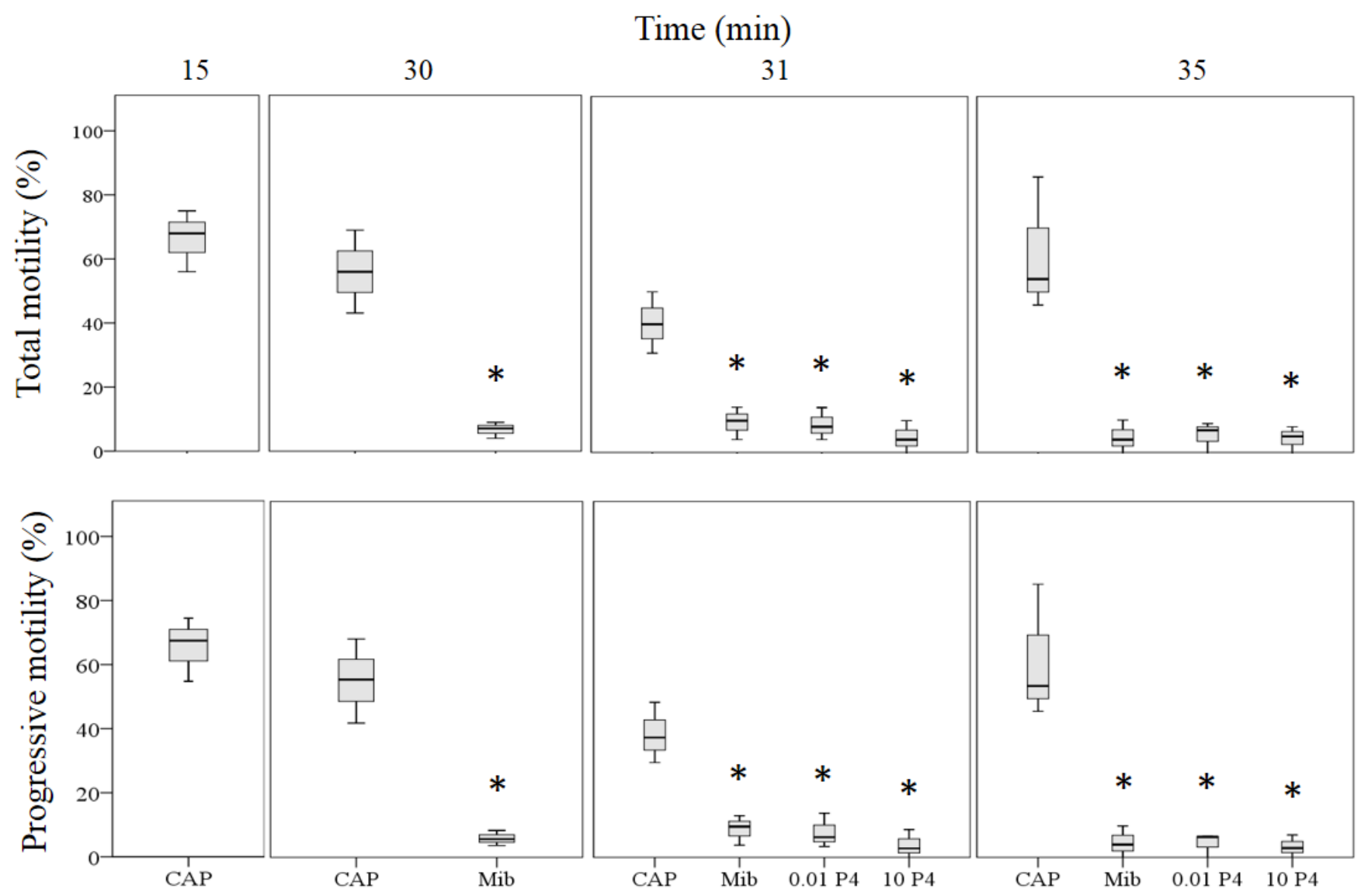
Figure 5

Time (min)
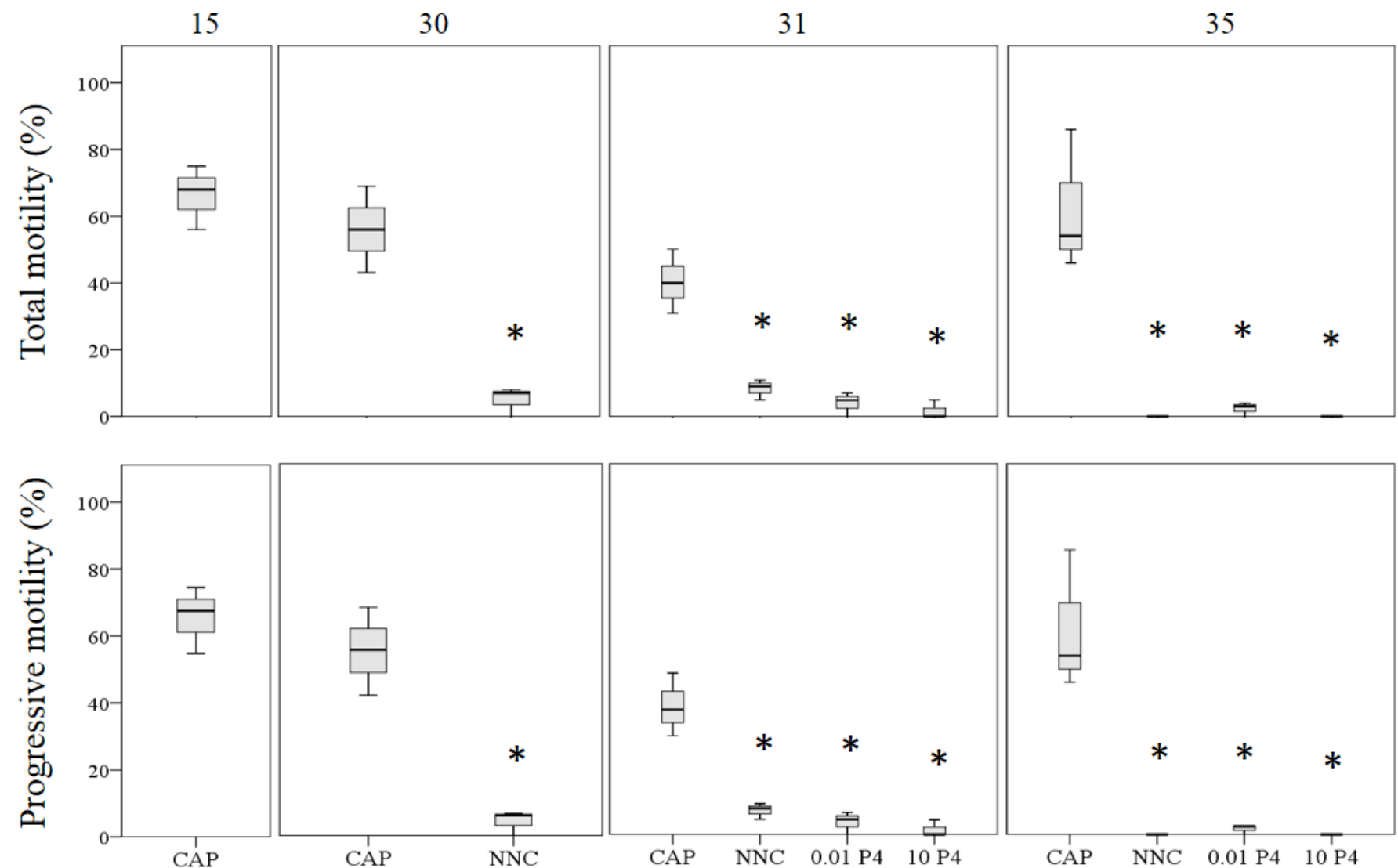


\section{SUPPLEMENTARY MATERIAL}

Supplementary Table 1. Effect of the capacitation-inducer sodium bicarbonate (35 mM of $\mathrm{NaHCO}_{3}$ ) in a conventional BTS extender (Control BTS) on total sperm motility (\%), progressive motility (\%) and percentages of live spermatozoa with damaged membrane (AnnV+/PI-; dMem) over incubation time. The values are expressed as mean \pm Standard Error of the Mean (SEM).

\begin{tabular}{|c|c|c|c|}
\hline $\begin{array}{l}\text { Time } \\
(\min )\end{array}$ & Variable & Control BTS & $\begin{array}{c}\mathrm{BTS}+35 \mathrm{mM} \\
\mathrm{NaHCO}_{3} \\
\end{array}$ \\
\hline \multirow{3}{*}{5} & Total motility & $65.4 \pm 25.95$ & $68.0 \pm 17.65$ \\
\hline & $\begin{array}{l}\text { Progressive } \\
\text { motility }\end{array}$ & $64.5 \pm 26.50$ & $65.9 \pm 18.00$ \\
\hline & dMem & $4.7 \pm 0.87$ & $3.8 \pm 0.43^{\mathrm{a}}$ \\
\hline \multirow{3}{*}{10} & Total motility & $57.3 \pm 27.27$ & $52.6 \pm 25.66$ \\
\hline & $\begin{array}{l}\text { Progressive } \\
\text { motility }\end{array}$ & $54.6 \pm 26.92$ & $50.7 \pm 25.28$ \\
\hline & dMem & $3.9 \pm 0.37$ & $1.5 \pm 0.78^{\mathrm{a}, \mathrm{b}}$ \\
\hline \multirow{3}{*}{15} & Total motility & $70.2 \pm 17.98$ & $56.9 \pm 22.99$ \\
\hline & $\begin{array}{l}\text { Progressive } \\
\text { motility }\end{array}$ & $68.8 \pm 19.23$ & $54.9 \pm 23.57$ \\
\hline & dMem & $3.1 \pm 0.71$ & $1.4 \pm 0.42^{\mathrm{b}, \mathrm{c}}$ \\
\hline \multirow{3}{*}{30} & Total motility & $58.6 \pm 27.97$ & $47.7 \pm 24.93$ \\
\hline & $\begin{array}{l}\text { Progressive } \\
\text { motility }\end{array}$ & $57.6 \pm 28.15$ & $45.1 \pm 23.87$ \\
\hline & dMem & $7.1 \pm 2.59$ & $2.3 \pm 1.33^{\mathrm{a}, \mathrm{b}}$ \\
\hline \multirow{3}{*}{60} & Total motility & $34.0 \pm 27.75$ & $4.4 \pm 2.99$ \\
\hline & $\begin{array}{c}\text { Progressive } \\
\text { motility }\end{array}$ & $32.6 \pm 27.33$ & $2.73 \pm 1.79$ \\
\hline & dMem & $1.3 \pm 0.27$ & $0.5 \pm 0.14^{\mathrm{a}, \mathrm{b}}$ \\
\hline
\end{tabular}


Supplementary Table 2. Effect of different concentrations of exogenous progesterone on boar sperm variables (total motility (\%), progressive motility (\%), dead sperm with damaged acrosomes (PNA+/PI+; dACR), sperm viability (PNA-/PI-; Viab) and mitochondrial integrity (MT+/PI-; MI)) over incubation time. Values are expressed as mean \pm Standard Error of the Mean (SEM).

\begin{tabular}{|c|c|c|c|c|c|c|c|c|c|}
\hline \multirow{2}{*}{$\begin{array}{l}\text { Time } \\
\text { (min) }\end{array}$} & \multirow{2}{*}{ Variable } & \multirow{2}{*}{ Control BTS } & \multirow{2}{*}{$\begin{array}{l}\text { Control } \\
\text { Ethanol }\end{array}$} & \multicolumn{6}{|c|}{ Progesterone $(\mu \mathrm{M})$} \\
\hline & & & & 0.01 & 0.1 & 1 & 2.5 & 5 & 10 \\
\hline \multirow{5}{*}{5} & $\begin{array}{c}\text { Total } \\
\text { motility }\end{array}$ & $81.7 \pm 6.06^{\mathrm{a}, \mathrm{b}}$ & $63.6 \pm 22.43$ & $84.3 \pm 6.67$ & $66.3 \pm 18.71$ & $88.3 \pm 1.42^{\mathrm{a}, \mathrm{b}}$ & $76.6 \pm 5.88$ & $90.3 \pm 1.19^{\mathrm{a}}$ & $78.0 \pm 14.50$ \\
\hline & $\begin{array}{c}\text { Progressive } \\
\text { motility }\end{array}$ & $80.3 \pm 6.09$ & $59.8 \pm 23.24$ & $82.7 \pm 6.18$ & $62.9 \pm 19.11$ & $86.9 \pm 1.84^{\mathrm{a}, \mathrm{b}}$ & $73.6 \pm 6.03$ & $88.7 \pm 2.09^{a}$ & $74.5 \pm 16.47$ \\
\hline & $\mathrm{dACR}$ & $6.8 \pm 0.42$ & $6.9 \pm 0.46$ & $7.1 \pm 1.02$ & $6.7 \pm 0.85$ & $6.2 \pm 0.29^{\mathrm{a}, \mathrm{b}}$ & $6.9 \pm 0.76$ & $6.5 \pm 1.15^{\mathrm{a}, \mathrm{b}}$ & $5.0 \pm 0.53$ \\
\hline & Viab & $91.9 \pm 0.11$ & $91.9 \pm 0.01$ & $91.4 \pm 0.65^{\mathrm{a}, \mathrm{b}}$ & $91.9 \pm 0.51$ & $92.5 \pm 0.07^{\mathrm{a}}$ & $91.7 \pm 0.68^{\mathrm{a}, \mathrm{b}}$ & $91.9 \pm 0.87^{\mathrm{a}, \mathrm{b}}$ & $92.2 \pm 1.00$ \\
\hline & MI & $89.6 \pm 1.63^{\mathrm{a}}$ & $90.6 \pm 1.16^{\mathrm{a}}$ & $89.2 \pm 2.08$ & $89.6 \pm 2.01^{\mathrm{a}, \mathrm{b}}$ & $90.1 \pm 1.35^{\mathrm{a}}$ & $90.6 \pm 1.30^{\mathrm{a}}$ & $91.3 \pm 1.53$ & $93.1 \pm 0.83$ \\
\hline \multirow{5}{*}{10} & $\begin{array}{c}\text { Total } \\
\text { motility }\end{array}$ & $79.3 \pm 8.79^{\mathrm{a}, \mathrm{b}}$ & $68.3 \pm 15.20$ & $81.7 \pm 5.84$ & $70.4 \pm 10.83$ & $86.7 \pm 2.85^{a}$ & $84.0 \pm 5.44$ & $83.0 \pm 3.79^{\mathrm{a}, \mathrm{b}}$ & $82.7 \pm 6.89$ \\
\hline & $\begin{array}{c}\text { Progressive } \\
\text { motility }\end{array}$ & $78.5 \pm 8.85$ & $65.5 \pm 15.19$ & $80.8 \pm 6.00$ & $68.1 \pm 10.4$ & $85.4 \pm 3.14^{\mathrm{a}}$ & $81.2 \pm 6.48$ & $81.9 \pm 4.42^{\mathrm{a}}$ & $81.5 \pm 7.46$ \\
\hline & $\mathrm{dACR}$ & $7.1 \pm 0.82$ & $6.9 \pm 0.60$ & $7.1 \pm 0.62$ & $6.8 \pm 0.53$ & $6.9 \pm 0.70^{\mathrm{a}, \mathrm{b}}$ & $6.8 \pm 0.61$ & $7.1 \pm 0.61^{\mathrm{a}}$ & $7.5 \pm 0.85$ \\
\hline & Viab & $91.5 \pm 0.48$ & $91.9 \pm 0.27$ & $91.6 \pm 0.21^{\mathrm{a}, \mathrm{b}}$ & $91.9 \pm 0.10$ & $91.6 \pm 0.33^{\mathrm{a}, \mathrm{b}}$ & $91.8 \pm 0.23^{\mathrm{a}}$ & $91.3 \pm 0.24^{\mathrm{a}}$ & $91.0 \pm 0.51$ \\
\hline & MI & $82.4 \pm 5.51^{\mathrm{a}, \mathrm{b}}$ & $82.3 \pm 5.44^{\mathrm{a}, \mathrm{b}}$ & $82.5 \pm 4.97$ & $86.4 \pm 3.25^{\mathrm{a}, \mathrm{b}}$ & $87.7 \pm 2.66^{\mathrm{a}}$ & $88.3 \pm 2.37^{\mathrm{a}}$ & $87.4 \pm 2.63$ & $87.9 \pm 2.45$ \\
\hline \multirow{5}{*}{15} & $\begin{array}{c}\text { Total } \\
\text { motility }\end{array}$ & $71.3 \pm 18.65^{\mathrm{a}}$ & $67.9 \pm 20.10$ & $80.6 \pm 10.32$ & $65.0 \pm 20.17$ & $85.0 \pm 5.99^{\mathrm{a}, \mathrm{b}}$ & $70.0 \pm 18.06$ & $89.3 \pm 3.18^{a}$ & $76.3 \pm 15.66$ \\
\hline & $\begin{array}{c}\text { Progressive } \\
\text { motility }\end{array}$ & $69.5 \pm 18.99$ & $66.2 \pm 20.54$ & $78.5 \pm 10.56$ & $63.2 \pm 19.70$ & $82.9 \pm 6.25^{\mathrm{a}, \mathrm{b}}$ & $67.7 \pm 18.25$ & $88.0 \pm 3.73^{a}$ & $75.0 \pm 15.94$ \\
\hline & $\mathrm{dACR}$ & $7.0 \pm 0.50$ & $7.0 \pm 0.42$ & $7.8 \pm 0.26$ & $7.7 \pm 0.27$ & $8.2 \pm 0.37^{\mathrm{a}}$ & $7.2 \pm 0.40$ & $7.8 \pm 0.74^{\mathrm{a}, \mathrm{b}}$ & $8.1 \pm 1.02$ \\
\hline & Viab & $91.6 \pm 0.17$ & $91.6 \pm 0.13$ & $90.4 \pm 0.52^{\mathrm{a}}$ & $90.7 \pm 0.31$ & $90.1 \pm 0.19^{b}$ & $90.4 \pm 0.16^{\mathrm{b}, \mathrm{c}}$ & $90.5 \pm 0.58^{\mathrm{a}, \mathrm{b}}$ & $90.4 \pm 0.75$ \\
\hline & MI & $70.5 \pm 10.40^{\mathrm{a}, \mathrm{b}}$ & $73.4 \pm 9.05^{\mathrm{a}, \mathrm{b}}$ & $70.8 \pm 6.41$ & $74.4 \pm 7.06^{\mathrm{a}}$ & $75.9 \pm 6.02^{\mathrm{a}, \mathrm{b}}$ & $73.2 \pm 8.47^{\mathrm{a}, \mathrm{b}}$ & $76.1 \pm 7.59$ & $79.0 \pm 6.33$ \\
\hline \multirow{5}{*}{30} & $\begin{array}{c}\text { Total } \\
\text { motility }\end{array}$ & $59.0 \pm 17.52^{\mathrm{a}, \mathrm{b}}$ & $44.0 \pm 31.00$ & $58.4 \pm 20.76$ & $60.0 \pm 19.01$ & $78.0 \pm 11.76^{\mathrm{a}, \mathrm{b}}$ & $76.9 \pm 8.20$ & $77.6 \pm 8.39^{a . b}$ & $81.0 \pm 9.31$ \\
\hline & $\begin{array}{c}\text { Progressive } \\
\text { motility }\end{array}$ & $57.0 \pm 17.51$ & $42.4 \pm 29.4$ & $56.1 \pm 20.9$ & $57.8 \pm 19.23$ & $76.2 \pm 12.66^{\mathrm{a}, \mathrm{b}}$ & $75.5 \pm 8.34$ & $76.1 \pm 8.27^{\mathrm{a}, \mathrm{b}}$ & $78.6 \pm 10.48$ \\
\hline & dACR & $9.3 \pm 0.26$ & $8.9 \pm 0.51$ & $9.6 \pm 0.33$ & $9.2 \pm 0.37$ & $9.9 \pm 0.48^{b}$ & $10.2 \pm 0.82$ & $10.8 \pm 0.57^{\mathrm{b}}$ & $10.5 \pm 0.69$ \\
\hline & Viab & $88.2 \pm 0.60$ & $89.6 \pm 0.11$ & $88.0 \pm 0.62^{\mathrm{b}}$ & $88.3 \pm 0.54$ & $87.8 \pm 0.18^{b}$ & $87.3 \pm 0.39^{c}$ & $86.6 \pm 0.11^{\mathrm{b}, \dagger}$ & $86.7 \pm 0.18$ \\
\hline & MI & $59.6 \pm 7.32^{\mathrm{a}, \mathrm{b}}$ & $49.7 \pm 0.54^{\mathrm{a}, \mathrm{b}}$ & $58.2 \pm 5.07$ & $59.8 \pm 7.29^{\mathrm{b}}$ & $63.0 \pm 5.87^{\mathrm{b}}$ & $58.4 \pm 10.53^{\mathrm{a}, \mathrm{b}}$ & $57.5 \pm 9.97$ & $61.4 \pm 8.58$ \\
\hline \multirow{5}{*}{60} & $\begin{array}{c}\text { Total } \\
\text { motility }\end{array}$ & $35.3 \pm 17.69^{b}$ & $30.6 \pm 19.52$ & $24.6 \pm 16.88$ & $25.0 \pm 19.31$ & $45.0 \pm 3.79^{b}$ & $44.0 \pm 8.58$ & $43.0 \pm 16.09^{b}$ & $61.3 \pm 4.41$ \\
\hline & $\begin{array}{c}\text { Progressive } \\
\text { motility }\end{array}$ & $32.5 \pm 16.23$ & $27.4 \pm 17.80$ & $21.8 \pm 15.56$ & $22.6 \pm 18.34$ & $40.7 \pm 3.76^{b}$ & $39.5 \pm 8.60$ & $38.9 \pm 15.66$ & $56.7 \pm 4.39$ \\
\hline & dACR & $10.0 \pm 0.44$ & $10.0 \pm 1.03$ & $10.0 \pm 0.59$ & $10.0 \pm 0.55$ & $10.4 \pm 0.51^{\mathrm{a}, \mathrm{b}}$ & $10.5 \pm 0.79$ & $11.7 \pm 1.01^{\mathrm{a}, \mathrm{b}}$ & $10.5 \pm 0.79$ \\
\hline & Viab & $85.8 \pm 1.58$ & $86.2 \pm 2.28$ & $85.7 \pm 1.23^{\mathrm{a}, \mathrm{b}}$ & $86.0 \pm 1.90$ & $85.8 \pm 1.00^{\mathrm{a}, \mathrm{b}}$ & $85.3 \pm 0.45^{\mathrm{a}, \mathrm{b}, \mathrm{c}}$ & $82.4 \pm 3.64^{\mathrm{a}, \mathrm{b}}$ & $83.4 \pm 1.84$ \\
\hline & MI & $26.8 \pm 2.46^{\mathrm{b}}$ & $25.9 \pm 3.48^{\mathrm{b}}$ & $21.2 \pm 6.06$ & $25.9 \pm 2.64^{\mathrm{a}, \mathrm{b}}$ & $27.8 \pm 2.47^{c}$ & $24.5 \pm 2.46^{\mathrm{b}}$ & $22.7 \pm 4.73$ & $25.7 \pm 4.82$ \\
\hline
\end{tabular}

$\overline{\mathrm{a}, \mathrm{b}, \mathrm{c}}$ denotes significant differences in the Time-Effect analysis. $\dagger$ denotes significant differences to the Control Ethanol. 
Supplementary Table 3. Effect of different concentrations of Mibefradil on boar sperm variables (total motility (\%), progressive motility (\%), dead spermatozoa with damaged acrosomes (PNA+/PI+; dACR), sperm viability (PNA-/PI-; Viab) and mitochondrial integrity (MT+/PI-; MI)) over incubation time. The values are expressed as mean \pm Standard Error of the Mean (SEM).

\begin{tabular}{|c|c|c|c|c|c|c|c|c|c|}
\hline \multirow{2}{*}{$\begin{array}{l}\text { Time } \\
\text { (min) }\end{array}$} & \multirow{2}{*}{ Variable } & \multirow{2}{*}{ Control BTS } & \multirow{2}{*}{$\begin{array}{l}\text { Control } \\
\text { DMSO }\end{array}$} & \multicolumn{6}{|c|}{ Mibefradil $(\mu \mathrm{M})$} \\
\hline & & & & 10 & 20 & 40 & 80 & 160 & 320 \\
\hline \multirow{5}{*}{5} & $\begin{array}{c}\text { Total } \\
\text { motility }\end{array}$ & $81.3 \pm 1.88^{\mathrm{a}}$ & $86.3 \pm 1.65^{\mathrm{a}, \mathrm{b}}$ & $79.7 \pm 3.18$ & $77.7 \pm 0.91$ & $82.6 \pm 4.43$ & $71.0 \pm 9.32^{\mathrm{a}, \mathrm{b}}$ & $65.0 \pm 11.02$ & $4.3 \pm 4.33^{*, \dagger}$ \\
\hline & $\begin{array}{c}\text { Progressive } \\
\text { motility }\end{array}$ & $79.0 \pm 3.47^{a}$ & $84.6 \pm 2.20^{\mathrm{a}, \mathrm{b}}$ & $76.8 \pm 4.61$ & $74.6 \pm 2.32$ & $81.6 \pm 4.86^{\mathrm{a}, \mathrm{b}}$ & $67.9 \pm 9.77^{\mathrm{a}, \mathrm{b}}$ & $61.3 \pm 11.43$ & $2.8 \pm 2.83^{*, \dagger}$ \\
\hline & dACR & $9.5 \pm 1.09$ & $9.4 \pm 0.63$ & $8.7 \pm 1.00$ & $9.4 \pm 1.54$ & $8.7 \pm 1.28$ & $9.2 \pm 1.56$ & $20.0 \pm 5.09^{a}$ & $81.3 \pm 1.67^{*, \dagger}$ \\
\hline & Viab & $87.9 \pm 1.94$ & $87.7 \pm 1.40$ & $88.4 \pm 1.94$ & $88.3 \pm 2.27$ & $88.6 \pm 1.99$ & $87.4 \pm 2.21$ & $61.2 \pm 5.80^{*}, \dagger$ & $0.9 \pm 0.60^{*, \dagger}$ \\
\hline & MI & $74.8 \pm 7.99$ & $7.1 \pm 7.25$ & $86.4 \pm 0.44$ & $87.4 \pm 3.37$ & $88.8 \pm 1.80$ & $87.3 \pm 3.27$ & $59.8 \pm 5.59$ & $0.2 \pm 0.13^{*, \dagger}$ \\
\hline \multirow{5}{*}{10} & $\begin{array}{c}\text { Total } \\
\text { motility }\end{array}$ & $80.0 \pm 2.25^{\mathrm{a}}$ & $54.0 \pm 27.06^{\mathrm{a}, \mathrm{b}}$ & $81.0 \pm 3.79$ & $72.3 \pm 4.67$ & $87.7 \pm 2.60$ & $76.3 \pm 3.17^{\mathrm{a}}$ & $50.3 \pm 14.86$ & $26.7 \pm 26.70$ \\
\hline & $\begin{array}{c}\text { Progressive } \\
\text { motility }\end{array}$ & $77.1 \pm 3.29^{\mathrm{a}}$ & $52.1 \pm 26.07^{\mathrm{a}, \mathrm{b}}$ & $78.7 \pm 4.54$ & $70.6 \pm 4.12$ & $85.9 \pm 2.12^{\mathrm{a}, \mathrm{b}}$ & $73.1 \pm 2.63^{\mathrm{a}}$ & $45.5 \pm 14.38$ & $26.1 \pm 26.10$ \\
\hline & dACR & $8.8 \pm 1.00$ & $10.0 \pm 0.67$ & $9.5 \pm 0.54$ & $9.3 \pm 0.74$ & $9.9 \pm 0.45$ & $11.0 \pm 0.83$ & $50.2 \pm 8.92^{\mathrm{a}, \mathrm{b}, *, \dagger}$ & $95.9 \pm 0.48^{*, \dagger}$ \\
\hline & Viab & $88.0 \pm 1.54$ & $86.9 \pm 1.51$ & $87.6 \pm 1.25$ & $88.0 \pm 1.54$ & $87.1 \pm 1.02$ & $84.6 \pm 1.73$ & $27.5 \pm 12.75^{*, \dagger}$ & $0.0 \pm 0.00^{*, \dagger}$ \\
\hline & MI & $70.5 \pm 11.26$ & $69.2 \pm 10.34$ & $79.3 \pm 6.15$ & $84.8 \pm 3.44$ & $86.7 \pm 0.98$ & $85.9 \pm 1.92$ & $26.9 \pm 12.72^{*, \dagger}$ & $0.2 \pm 0.01^{*, \dagger}$ \\
\hline \multirow{5}{*}{15} & $\begin{array}{c}\text { Total } \\
\text { motility }\end{array}$ & $78.9 \pm 7.04^{\mathrm{a}, \mathrm{b}}$ & $74.4 \pm 7.37^{\mathrm{a}, \mathrm{b}}$ & $72.3 \pm 9.19$ & $77.3 \pm 3.93$ & $75.3 \pm 8.41$ & $78.3 \pm 7.70^{\mathrm{a}, \mathrm{b}}$ & $36.4 \pm 19.64$ & $0.0 \pm 0.00^{*, \dagger}$ \\
\hline & $\begin{array}{c}\text { Progressive } \\
\text { motility }\end{array}$ & $75.7 \pm 9.31^{\mathrm{a}, \mathrm{b}}$ & $69.7 \pm 8.58^{\mathrm{a}}$ & $68.7 \pm 11.23$ & $74.9 \pm 4.72$ & $72.7 \pm 8.55^{\mathrm{a}, \mathrm{b}}$ & $74.2 \pm 9.04^{\mathrm{a}, \mathrm{b}}$ & $34.8 \pm 19.09$ & $0.0 \pm 0.00^{*}, \dagger$ \\
\hline & dACR & $10.0 \pm 0.77$ & $10.6 \pm 1.09$ & $10.9 \pm 0.65$ & $10.4 \pm 0.17$ & $11.4 \pm 1.17$ & $15.7 \pm 3.80$ & $71.8 \pm 5.88^{\mathrm{a}, \mathrm{b}^{*}, \dagger}$ & $98.7 \pm 0.61^{*, \dagger}$ \\
\hline & Viab & $87.2 \pm 1.44$ & $86.6 \pm 1.51$ & $85.9 \pm 1.25$ & $86.5 \pm 0.94$ & $85.1 \pm 1.43$ & $79.2 \pm 4.18$ & $4.8 \pm 3.12^{*, \dagger}$ & $0 . \pm 0.00^{*, \dagger}$ \\
\hline & MI & $65.0 \pm 13.56$ & $63.3 \pm 14.31$ & $79.6 \pm 5.23$ & $83.9 \pm 2.64$ & $85.9 \pm 1.25$ & $80.1 \pm 4.19$ & $4.2 \pm 2.50^{*, \dagger}$ & $0.3 \pm 0.01^{*, \dagger}$ \\
\hline \multirow{5}{*}{30} & $\begin{array}{c}\text { Total } \\
\text { motility }\end{array}$ & $57.7 \pm 12.70^{\mathrm{a}, \mathrm{b}}$ & $46.3 \pm 12.33^{\mathrm{a}}$ & $40.3 \pm 6.12$ & $54.4 \pm 17.72$ & $70.0 \pm 12.31$ & $50.4 \pm 21.73^{\mathrm{a}}$ & $4.5 \pm 1.20$ & $0.0 \pm 0.00$ \\
\hline & $\begin{array}{c}\text { Progressive } \\
\text { motility }\end{array}$ & $52.7 \pm 14.27^{\mathrm{a}, \mathrm{b}}$ & $39.7 \pm 12.97^{\mathrm{a}, \mathrm{b}}$ & $35.6 \pm 5.63$ & $50.1 \pm 18.01$ & $65.9 \pm 13.00^{\mathrm{a}}$ & $48.5 \pm 22.19^{\mathrm{a}, \mathrm{b}}$ & $3.4 \pm 0.45$ & $0.0 \pm 0.00$ \\
\hline & dACR & $12.7 \pm 1.57$ & $13.5 \pm 2.00$ & $12.1 \pm 1.39$ & $12.9 \pm 1.35$ & $16.0 \pm 2.45$ & $30.9 \pm 10.32$ & $88.5 \pm 4.49^{\mathrm{a}, \mathrm{b},{ }^{*}, \dagger}$ & $98.4 \pm 0.79^{*}, \dagger$ \\
\hline & Viab & $83.8 \pm 1.54$ & $82.7 \pm 2.6$ & $84.1 \pm 1.91$ & $83.4 \pm 1.60$ & $79.4 \pm 2.74$ & $56.3 \pm 14.46$ & $0.6 \pm 0.58^{*, \dagger}$ & $0.0 \pm 0.00^{*, \dagger}$ \\
\hline & MI & $44.7 \pm 9.22$ & $42.2 \pm 8.32$ & $73.3 \pm 7.70$ & $77.4 \pm 4.00$ & $77.4 \pm 4.35$ & $55.0 \pm 13.74$ & $0.4 \pm 0.34^{*, \dagger}$ & $0.1 \pm 0.02^{*, \dagger}$ \\
\hline \multirow{5}{*}{60} & $\begin{array}{c}\text { Total } \\
\text { motility }\end{array}$ & $15.6 \pm 2.32^{b}$ & $21.6 \pm 11.81^{\mathrm{b}}$ & $17.7 \pm 10.27$ & $13.3 \pm 5.55$ & $40.3 \pm 14.80$ & $12.9 \pm 2.28^{b}$ & $0.0 \pm 0.00$ & $0.0 \pm 0.00$ \\
\hline & $\begin{array}{c}\text { Progressive } \\
\text { motility }\end{array}$ & $13.7 \pm 2.42^{\mathrm{b}}$ & $18.4 \pm 10.83^{b}$ & $15.2 \pm 9.90$ & $10.6 \pm 3.99$ & $37.1 \pm 13.25^{b}$ & $9.0 \pm 0.96$ & $0.0 \pm 0.00$ & $0.0 \pm 0.00$ \\
\hline & dACR & $12.2 \pm 0.85$ & $13.2 \pm 1.17$ & $14.8 \pm 2.29$ & $17.0 \pm 3.38$ & $35.2 \pm 12.02$ & $61.1 \pm 12.92^{\mathrm{b}, *, \dagger}$ & $97.3 \pm 0.50^{\mathrm{b}, *, \dagger}$ & $98.0 \pm 0.59^{*, \dagger}$ \\
\hline & Viab & $83.6 \pm 1.49$ & $79.4 \pm 3.56$ & $79.9 \pm 3.55$ & $77.2 \pm 4.83$ & $54.6 \pm 14.91$ & $23.6 \pm 14.40^{*}, \dagger$ & $0.4 \pm 0.02^{*, \dagger}$ & $0.2 \pm 0.01^{*, \dagger}$ \\
\hline & MI & $12.1 \pm 5.36$ & $11.5 \pm 7.02$ & $40.1 \pm 24.06$ & $49.1 \pm 21.58$ & $46.9 \pm 15.75$ & $23.8 \pm 14.63$ & $0.2 \pm 0.16$ & $0.4 \pm 0.03$ \\
\hline
\end{tabular}

a, b, c denotes significant differences in the Time-Effect analysis. * denotes significant differences to the Control BTS and $\dagger$ marks significant differences to the Control DMSO. 
Supplementary Table 4. Effect of different concentrations of NNC 55-0396 on boar sperm variables (total motility (\%), progressive motility (\%), dead spermatozoa with damaged acrosomes (PNA+/PI+; dACR), sperm viability (PNA-/PI-; Viab) and mitochondrial integrity (MT+/PI-; MI)) over incubation time. The values are expressed as mean \pm Standard Error of the Mean (SEM).

\begin{tabular}{|c|c|c|c|c|c|c|c|c|c|}
\hline \multirow{2}{*}{$\begin{array}{l}\text { Time } \\
(\min )\end{array}$} & \multirow{2}{*}{ Variable } & \multirow{2}{*}{ Control BTS } & \multirow{2}{*}{$\begin{array}{l}\text { Control } \\
\text { DMSO }\end{array}$} & \multicolumn{6}{|c|}{ NNC 55-0396 $(\mu \mathrm{M})$} \\
\hline & & & & 2.5 & 5 & 10 & 20 & 40 & 80 \\
\hline \multirow{5}{*}{5} & $\begin{array}{c}\text { Total } \\
\text { motility }\end{array}$ & $82.7 \pm 5.99$ & $70.3 \pm 8.63^{a}$ & $66.1 \pm 12.97$ & $69.7 \pm 10.73$ & $72.3 \pm 10.37$ & $73.6 \pm 0.88$ & $41.3 \pm 19.58$ & $3.7 \pm 3.67^{*}, \uparrow$ \\
\hline & $\begin{array}{c}\text { Progressive } \\
\text { motility }\end{array}$ & $80.2 \pm 7.72$ & $65.8 \pm 10.30^{a}$ & $62.0 \pm 15.54$ & $65.0 \pm 13.26$ & $69.2 \pm 11.04$ & $70.0 \pm 1.70$ & $38.2 \pm 19.90$ & $3.5 \pm 3.47^{*}$ \\
\hline & dACR & $7.9 \pm 0.23$ & $8.2 \pm 0.30$ & $7.9 \pm 0.29$ & $8.3 \pm 0.52$ & $8.4 \pm 0.27^{\mathrm{a}, \mathrm{b}}$ & $8.6 \pm 0.54$ & $18.1 \pm 9.45$ & $45.4 \pm 20.26$ \\
\hline & Viab & $89.2 \pm 1.20$ & $88.6 \pm 1.40$ & $89.2 \pm 1.29$ & $88.7 \pm 1.54$ & $88.5 \pm 1.45$ & $88.1 \pm 1.87^{\mathrm{a}, \mathrm{b}}$ & $70.4 \pm 16.86$ & $15.5 \pm 11.42$ \\
\hline & MI & $66.1 \pm 12.76$ & $66.5 \pm 11.7$ & $76.2 \pm 12.42^{\mathrm{a}}$ & $78.6 \pm 11.84$ & $84.4 \pm 5.81$ & $87.4 \pm 3.36^{\mathrm{a}}$ & $69.8 \pm 17.97$ & $14.2 \pm 11.77$ \\
\hline \multirow{5}{*}{10} & $\begin{array}{c}\text { Total } \\
\text { motility }\end{array}$ & $72.7 \pm 14.25$ & $75.6 \pm 7.23^{a}$ & $61.7 \pm 5.93$ & $67.9 \pm 3.06$ & $82.0 \pm 6.52$ & $77.3 \pm 7.90$ & $60.3 \pm 26.30$ & $4.3 \pm 2.19^{*, \dagger}$ \\
\hline & $\begin{array}{l}\text { Progressive } \\
\text { motility }\end{array}$ & $69.7 \pm 15.73$ & $73.0 \pm 8.15^{a}$ & $58.7 \pm 6.35$ & $64.9 \pm 3.76$ & $79.5 \pm 5.82$ & $73.3 \pm 9.67$ & $57.9 \pm 26.98$ & $3.4 \pm 1.88^{*, \dagger}$ \\
\hline & dACR & $8.3 \pm 0.42$ & $8.5 \pm 0.28$ & $8.6 \pm 0.53$ & $8.5 \pm 0.42$ & $8.0 \pm 0.17^{\mathrm{a}}$ & $8.1 \pm 0.21$ & $26.3 \pm 17.53$ & $67.6 \pm 12.53^{*, \dagger}$ \\
\hline & Viab & $89.0 \pm 1.29$ & $88.0 \pm 1.05$ & $88.4 \pm 1.37$ & $88.5 \pm 1.04$ & $89.1 \pm 1.20$ & $88.9 \pm 0.93^{\mathrm{a}, \mathrm{b}}$ & $61.4 \pm 25.09$ & $2.1 \pm 1.70$ \\
\hline & MI & $61.3 \pm 14.37$ & $60.2 \pm 14.36$ & $73.2 \pm 14.98^{\mathrm{a}}$ & $77.0 \pm 12.47$ & $81.3 \pm 8.80$ & $85.1 \pm 5.45^{\mathrm{a}, \mathrm{b}}$ & $59.8 \pm 26.02$ & $1.9 \pm 1.78$ \\
\hline \multirow{5}{*}{15} & $\begin{array}{c}\text { Total } \\
\text { motility }\end{array}$ & $75.3 \pm 11.77$ & $70.0 \pm 18.04^{\mathrm{a}}$ & $62.3 \pm 21.97$ & $67.3 \pm 11.26$ & $85.3 \pm 0.88$ & $73.6 \pm 12.01$ & $43.3 \pm 22.56$ & $1.3 \pm 1.33$ \\
\hline & $\begin{array}{c}\text { Progressive } \\
\text { motility }\end{array}$ & $71.6 \pm 14.15$ & $66.5 \pm 19.47^{a}$ & $60.0 \pm 22.93$ & $65.5 \pm 12.06$ & $82.8 \pm 1.81$ & $71.8 \pm 13.19$ & $41.3 \pm 22.70$ & $1.2 \pm 1.23$ \\
\hline & dACR & $9.04 \pm 0.76$ & $9.6 \pm 0.85$ & $9.4 \pm 0.56$ & $9.3 \pm 0.70$ & $9.3 \pm 0.23^{b}$ & $9.2 \pm 0.06$ & $33.5 \pm 20.62$ & $82.3 \pm 11.02^{*, \dagger}$ \\
\hline & Viab & $87.9 \pm 0.72$ & $87.0 \pm 1.34$ & $87.3 \pm 1.13$ & $87.2 \pm 0.98$ & $87.1 \pm 1.71$ & $87.2 \pm 1.32^{\mathrm{a}, \mathrm{b}}$ & $55.4 \pm 23.62$ & $0.2 \pm 0.14$ \\
\hline & MI & $59.2 \pm 14.86$ & $57.7 \pm 14.13$ & $70.0 \pm 15.89^{\mathrm{a}, \mathrm{b}}$ & $73.7 \pm 12.20$ & $79.1 \pm 9.92$ & $84.8 \pm 4.68^{\mathrm{a}, \mathrm{b}}$ & $54.7 \pm 24.13$ & $0.2 \pm 0.14$ \\
\hline \multirow{5}{*}{30} & $\begin{array}{c}\text { Total } \\
\text { motility }\end{array}$ & $50.0 \pm 10.69$ & $31.7 \pm 21.68^{\mathrm{a}}$ & $38.0 \pm 16.29$ & $26.0 \pm 13.20$ & $50.0 \pm 7.21$ & $55.7 \pm 14.31$ & $23.0 \pm 14.23$ & $6.3 \pm 6.33$ \\
\hline & $\begin{array}{l}\text { Progressive } \\
\text { motility }\end{array}$ & $47.0 \pm 11.13$ & $29.3 \pm 20.80^{\mathrm{a}}$ & $34.0 \pm 16.98$ & $27.3 \pm 10.82$ & $45.0 \pm 6.03$ & $53.1 \pm 14.77$ & $21.3 \pm 13.35$ & $5.4 \pm 5.40$ \\
\hline & dACR & $10.5 \pm 1.52$ & $11.5 \pm 1.88$ & $10.7 \pm 1.37$ & $10.5 \pm 1.50$ & $11.3 \pm 1.08^{\mathrm{a}, \mathrm{b}}$ & $12.5 \pm 1.16$ & $41.3 \pm 19.98^{*, \dagger}$ & $91.0 \pm 5.96^{*, \dagger}$ \\
\hline & Viab & $85.7 \pm 1.14$ & $83.9 \pm 2.00$ & $85.2 \pm 1.83$ & $85.7 \pm 1.37$ & $84.5 \pm 1.23$ & $81.7 \pm 0.97^{\mathrm{b}}$ & $44.1 \pm 19.75$ & $0.3 \pm 0.01$ \\
\hline & MI & $42.4 \pm 7.97$ & $38.3 \pm 9.35$ & $58.8 \pm 13.69^{\mathrm{a}, \mathrm{b}}$ & $61.3 \pm 13.73$ & $72.5 \pm 7.18$ & $78.8 \pm 3.67^{\mathrm{b}}$ & $33.1 \pm 17.28$ & $0.1 \pm 0.03$ \\
\hline \multirow{5}{*}{60} & $\begin{array}{c}\text { Total } \\
\text { motility }\end{array}$ & $11.7 \pm 10.22$ & $11.7 \pm 9.74^{b}$ & $20.0 \pm 18.07$ & $10.4 \pm 3.88$ & $33.3 \pm 11.29$ & $35.0 \pm 10.05$ & $7.6 \pm 4.07$ & $0.0 \pm 0.00$ \\
\hline & $\begin{array}{l}\text { Progressive } \\
\text { motility }\end{array}$ & $9.5 \pm 9.00$ & $9.4 \pm 8.89^{a}$ & $18.3 \pm 17.56$ & $7.6 \pm 1.83$ & $30.1 \pm 11.03$ & $30.2 \pm 9.06$ & $7.4 \pm 4.03$ & $0.0 \pm 0.00$ \\
\hline & dACR & $10.5 \pm 1.52$ & $11.1 \pm 1.23$ & $10.0 \pm 1.35$ & 10. $8 \pm 1.94$ & $12.2 \pm 2.24$ & $21.3 \pm 5.62$ & $58.5 \pm 18.41^{*, \dagger}$ & $84.4 \pm 13.66^{*, \dagger}$ \\
\hline & Viab & $84.7 \pm 1.05$ & $80.9 \pm 2.54$ & $84.4 \pm 1.75$ & $84.5 \pm 1.89$ & $81.6 \pm 2.05$ & $69.1 \pm 2.53^{\mathrm{a}, \mathrm{b}}$ & $23.9 \pm 11.09$ & $0.2 \pm 0.01$ \\
\hline & MI & $19.0 \pm 5.38$ & $16.4 \pm 7.77$ & $8.1 \pm 1.82^{b}$ & $17.8 \pm 12.77$ & $20.2 \pm 9.67$ & $35.8 \pm 16.93^{\mathrm{a}}$ & $22.8 \pm 11.65$ & $0.1 \pm 0.04$ \\
\hline
\end{tabular}

$\overline{\mathrm{a}, \mathrm{b}}$ denotes significant differences in the Time-Effect analysis. * denotes significant differences to the Control BTS and $\dagger$ marks significant differences to the Control DMSO. 
Supplementary Table 5. Effect of the increased availability of $\mathrm{Ca}^{2+}$ in Control BTS, BTS without EDTA, and BTS without EDTA with addition of capacitation levels of sodium bicarbonate (35 $\mathrm{mM}$ of $\mathrm{NaHCO}_{3}$ ) on sperm variables (total motility (\%), progressive motility (\%), dead sperm with damaged acrosomes (PNA+/PI+; Viab), sperm viability (PNA-/PI-; $\mathrm{dACR}$ ) and mitochondrial integrity (MT+/PI-; MI)) over incubation time. The values are expressed as mean \pm Standard Error of the Mean (SEM).

\begin{tabular}{|c|c|c|c|c|}
\hline Time (min) & Variable & Control BTS & $\begin{array}{l}\text { BTS without } \\
\text { EDTA }\end{array}$ & $\begin{array}{c}\text { BTS without } \\
\text { EDTA + } 35 \mathrm{mM} \\
\mathrm{NaHCO}_{3} \\
\end{array}$ \\
\hline \multirow{5}{*}{5} & Total motility & $93.7 \pm 0.88$ & $79.2 \pm 2.35^{*}$ & $88.3 \pm 4.77^{a}$ \\
\hline & $\begin{array}{l}\text { Progressive } \\
\text { motility }\end{array}$ & $93.3 \pm 0.88$ & $77.8 \pm 3.10$ & $87.6 \pm 4.92^{\mathrm{a}}$ \\
\hline & dACR & $5.7 \pm 1.04$ & $6.8 \pm 0.50$ & $7.7 \pm 0.42^{\mathrm{a}}$ \\
\hline & Viab & $92.9 \pm 1.06^{\mathrm{a}}$ & $91.8 \pm 0.61^{\mathrm{a}, \mathrm{b}}$ & $90.7 \pm 0.54^{\mathrm{a}}$ \\
\hline & MI & $59.2 \pm 4.43$ & $56.3 \pm 0.62$ & $53.4 \pm 2.68^{\mathrm{a}}$ \\
\hline \multirow{5}{*}{10} & Total motility & $95.1 \pm 1.51$ & $94.9 \pm 2.48$ & $81.3 \pm 2.69^{\mathrm{a}, *, \dagger}$ \\
\hline & $\begin{array}{l}\text { Progressive } \\
\text { motility }\end{array}$ & $94.7 \pm 1.53$ & $94.5 \pm 2.72$ & $80.8 \pm 2.74^{\mathrm{a}, \mathrm{b}, *, \dagger}$ \\
\hline & dACR & $6.9 \pm 0.22$ & $6.9 \pm 0.15$ & $10.3 \pm 0.24^{\mathrm{a}, *, \dagger}$ \\
\hline & Viab & $91.7 \pm 0.22^{\mathrm{a}, \mathrm{b}}$ & $91.8 \pm 0.15^{\mathrm{a}}$ & $88.1 \pm 0.33^{\mathrm{a}, \mathrm{b}, \mathrm{c}, *, \dagger}$ \\
\hline & MI & $53.1 \pm 3.89$ & $51.3 \pm 3.66$ & $51.9 \pm 1.83^{\mathrm{a}}$ \\
\hline \multirow{5}{*}{15} & Total motility & $94.7 \pm 1.35$ & $89.3 \pm 6.55$ & $88.7 \pm 2.30^{\mathrm{a}}$ \\
\hline & $\begin{array}{l}\text { Progressive } \\
\text { motility }\end{array}$ & $94.5 \pm 1.40$ & $89.1 \pm 6.51$ & $87.9 \pm 2.55^{\mathrm{a}}$ \\
\hline & dACR & $8.9 \pm 1.90$ & $6.5 \pm 0.17$ & $13.4 \pm 0.59^{\mathrm{b}, \dagger}$ \\
\hline & Viab & $89.3 \pm 1.96^{\mathrm{a}, \mathrm{b}}$ & $92.2 \pm 0.16^{\mathrm{b}}$ & $84.7 \pm 0.67^{b, \dagger}$ \\
\hline & MI & $53.6 \pm 1.21$ & $51.9 \pm 0.73$ & $47.6 \pm 0.93^{\mathrm{a}, \mathrm{b}}$ \\
\hline \multirow{5}{*}{30} & Total motility & $89.1 \pm 4.40$ & $94.0 \pm 1.18$ & $79.1 \pm 6.12^{\mathrm{a}, \mathrm{b}}$ \\
\hline & $\begin{array}{l}\text { Progressive } \\
\text { motility }\end{array}$ & $88.8 \pm 4.27$ & $93.7 \pm 1.34$ & $70.6 \pm 11.77^{\mathrm{a}, \mathrm{b}}$ \\
\hline & dACR & $5.8 \pm 0.91$ & $6.4 \pm 0.21$ & $17.5 \pm 1.93^{\mathrm{a}, \mathrm{b}, \mathrm{c}, *, \dagger}$ \\
\hline & Viab & $92.5 \pm 0.87^{a}$ & $92.0 \pm 0.30^{\mathrm{a}, \mathrm{b}}$ & $79.8 \pm 1.83^{\mathrm{a}, \mathrm{b}, \mathrm{c}, *, \dagger}$ \\
\hline & MI & $54.0 \pm 4.60$ & $48.2 \pm 4.19$ & $41.4 \pm 0.38^{\mathrm{a}, \mathrm{b}}$ \\
\hline \multirow{5}{*}{60} & Total motility & $52.3 \pm 14.66$ & $41.0 \pm 19.07$ & $2.7 \pm 2.67^{b}$ \\
\hline & $\begin{array}{l}\text { Progressive } \\
\text { motility }\end{array}$ & $47.9 \pm 14.07$ & $36.9 \pm 20.29$ & $1.5 \pm 1.53^{\mathrm{b}}$ \\
\hline & dACR & $7.0 \pm 0.56$ & $7.3 \pm 0.70$ & $32.7 \pm 0.20^{\mathrm{c}, *, \dagger}$ \\
\hline & Viab & $88.1 \pm 0.95^{\mathrm{b}}$ & $88.3 \pm 1.22^{\mathrm{a}, \mathrm{b}}$ & $61.6 \pm 0.83^{\mathrm{c}, *, \dagger}$ \\
\hline & MI & $30.2 \pm 5.67$ & $29.5 \pm 4.81$ & $21.9 \pm 1.94^{\mathrm{b}, *, \dagger}$ \\
\hline
\end{tabular}

a, b denotes significant differences in the Time-Effect analysis. * denotes significant differences to the Control BTS and $\dagger$ marks significant differences to the BTS without EDTA. 
Supplementary Table 6. Sperm changes (total motility (\%) and progressive motility (\%)) following addition of either $0.01 \mu \mathrm{M}$ or $10 \mu \mathrm{M}$ progesterone after pre-incubation of boar spermatozoa in capacitating medium at $38{ }^{\circ} \mathrm{C}$ for $30 \mathrm{~min}$. The values are expressed as mean \pm Standard Error of the Mean (SEM).

\begin{tabular}{c|c|c|cc}
\hline \multirow{2}{*}{$\begin{array}{c}\text { Time } \\
(\mathrm{min})\end{array}$} & Sperm motility & Capacitated & \multicolumn{2}{|c}{ Progesterone $(\mu \mathrm{M})$} \\
\cline { 4 - 5 } & Control & 0.01 & 10 \\
\hline \multirow{2}{*}{1} & Total & $53.1 \pm 4.70$ & $50.8 \pm 3.74$ & $39.3 \pm 16.93$ \\
& Progressive & $51.0 \pm 4.38$ & $48.7 \pm 4.61$ & $37.6 \pm 17.21$ \\
\hline \multirow{2}{*}{5} & Total & $63.8 \pm 9.12$ & $67.9 \pm 6.88$ & $47.8 \pm 14.98$ \\
& Progressive & $62.1 \pm 9.70$ & $66.6 \pm 6.92$ & $45.8 \pm 15.19$ \\
\hline \multirow{2}{*}{10} & Total & $28.3 \pm 8.58$ & $57.3 \pm 6.78$ & $31.4 \pm 18.68$ \\
& Progressive & $26.1 \pm 8.78$ & $56.0 \pm 6.32$ & $29.6 \pm 18.87$ \\
\hline \multirow{2}{*}{15} & Total & $25.0 \pm 3.61$ & $45.1 \pm 10.55$ & $24.3 \pm 19.23$ \\
& Progressive & $22.7 \pm 3.54$ & $43.9 \pm 10.96$ & $23.6 \pm 18.83$ \\
\hline \multirow{2}{*}{30} & Total & $23.2 \pm 6.58$ & $30.2 \pm 15.18$ & $6.5 \pm 3.43$ \\
& Progressive & $21.0 \pm 6.24$ & $27.9 \pm 14.18$ & $5.8 \pm 3.09$ \\
\hline
\end{tabular}

a,b denotes significant differences in the Time-Effect analysis. 


\section{Supplementary Figure S1}

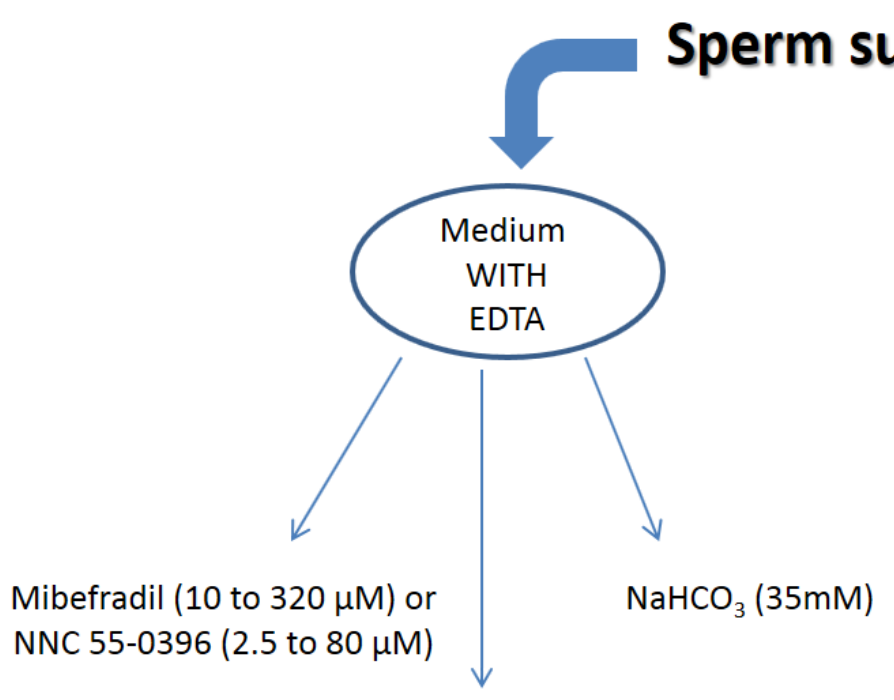

Progesterone (0.01 to $10 \mu \mathrm{M})$

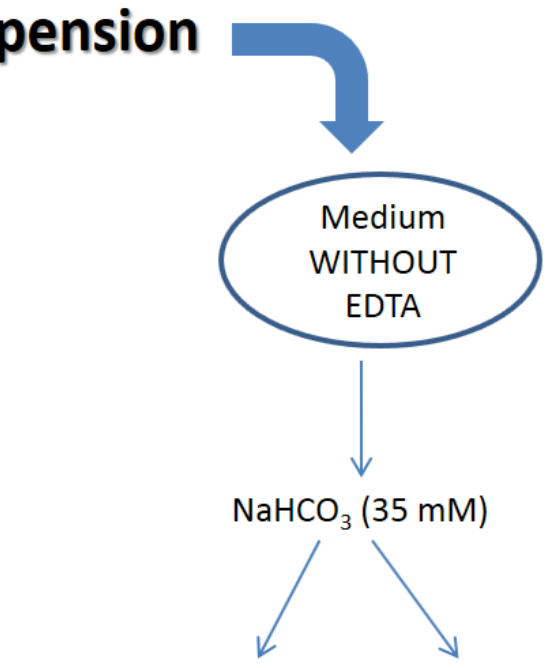

Progesterone (0.01 and $10 \mu \mathrm{M})$
Mibefradil $(40 \mu \mathrm{M})$ or NNC 55-0396 (20 $\mu \mathrm{M})$

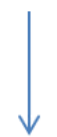

Progesterone (0.01 and $10 \mu \mathrm{M}$ ) 
Supplementary Figure S2
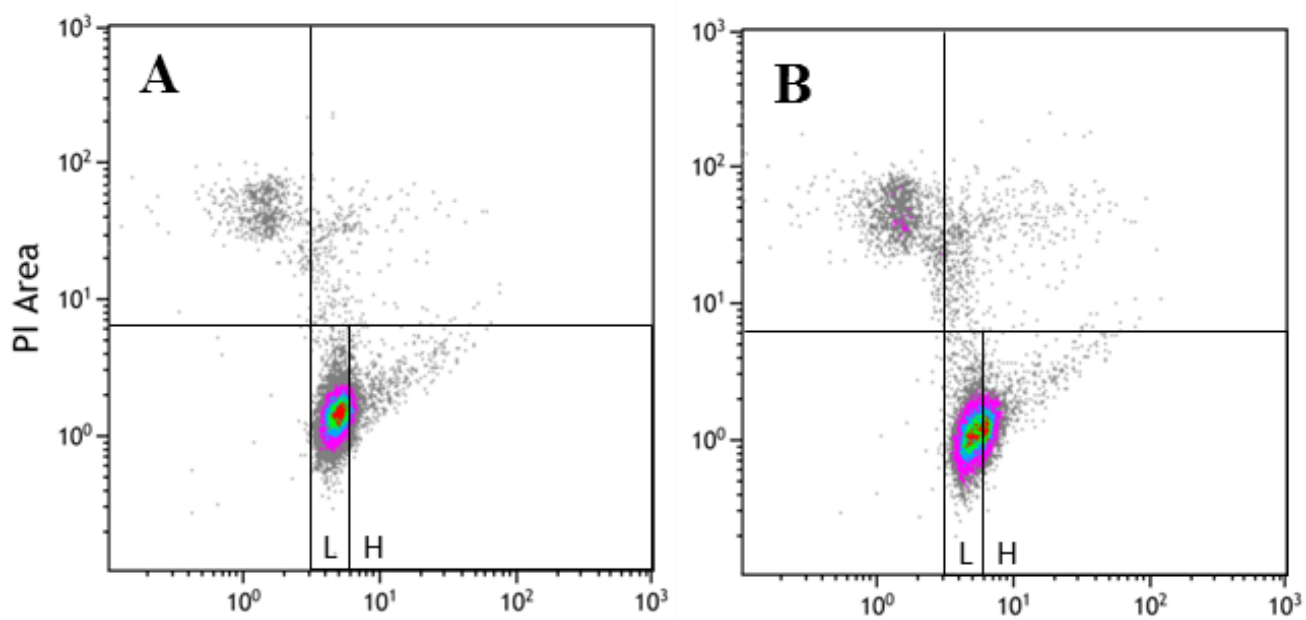

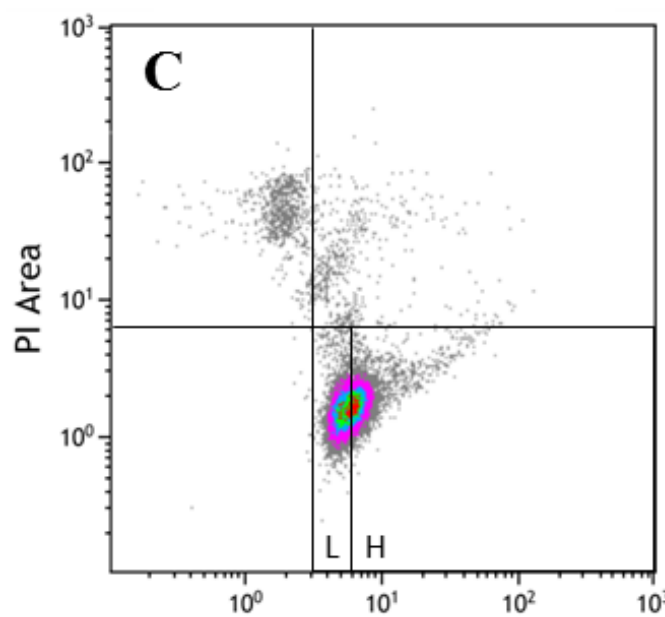

Fluo-3-AM Area

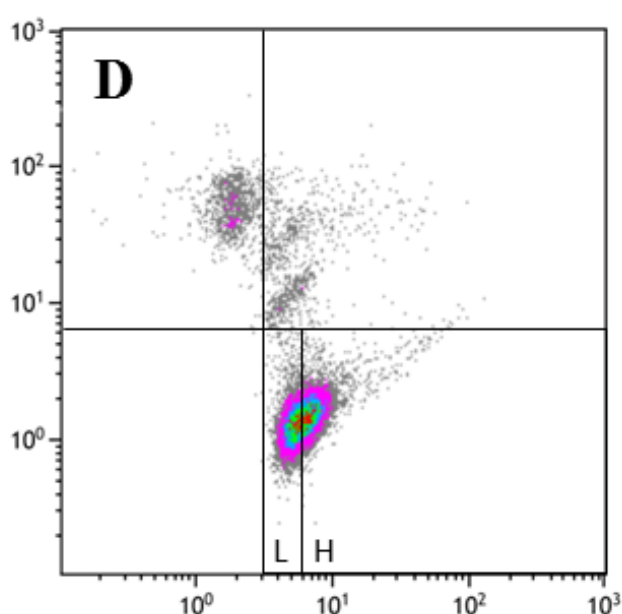

Fluo-3-AM Area 


\section{Supplementary Figure S3}
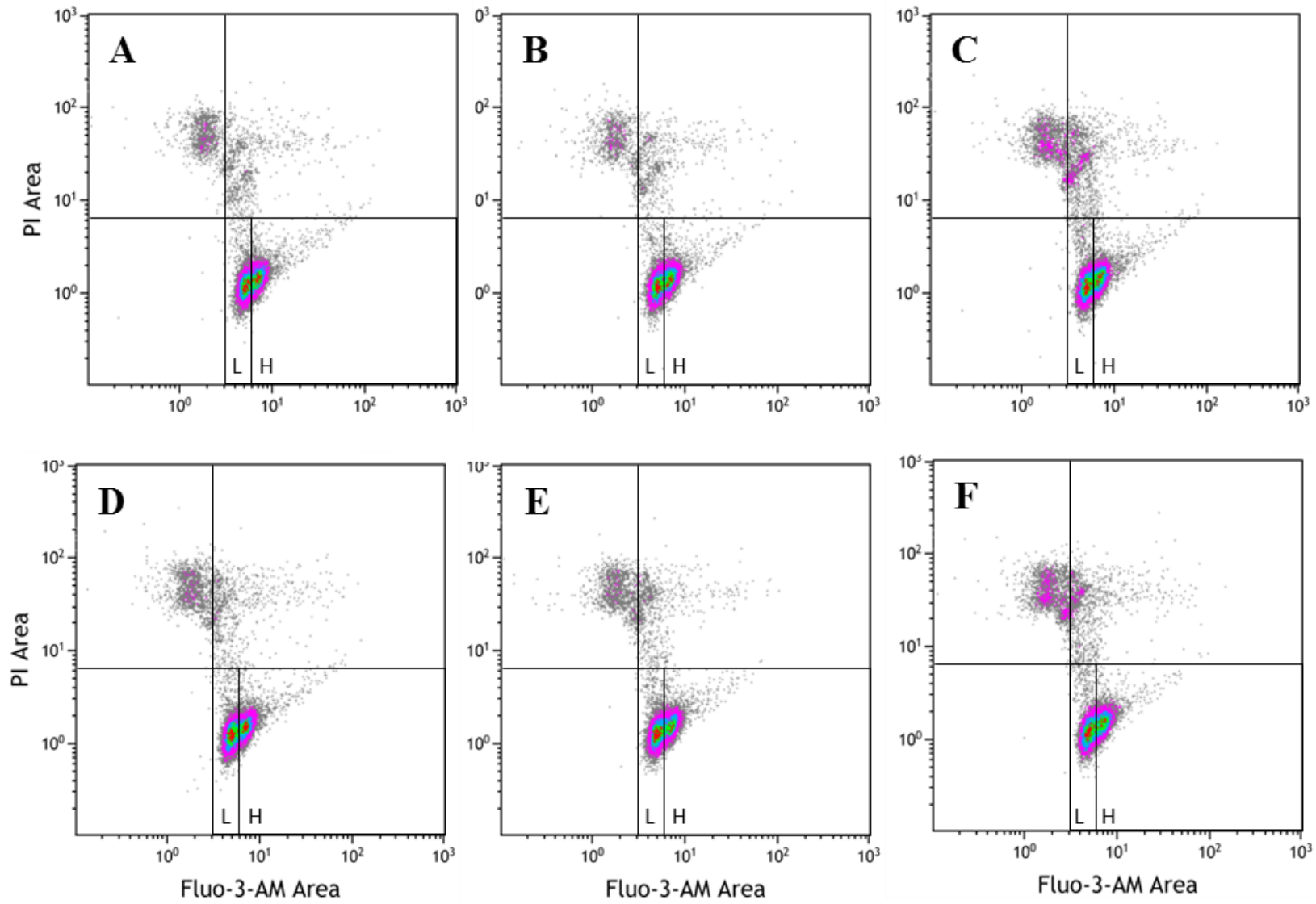


\section{SUPPLEMENTARY MATERIAL (GRAPHS)}

Set of graphs 1. Effect of the capacitation-inducer sodium bicarbonate ( $35 \mathrm{mM}$ of $\left.\mathrm{NaHCO}_{3}\right)$ in a conventional BTS extender (Control BTS) on total sperm motility (\%), progressive motility (\%) and percentages of live spermatozoa with damaged membrane (AnnV+/PI-) over incubation time.
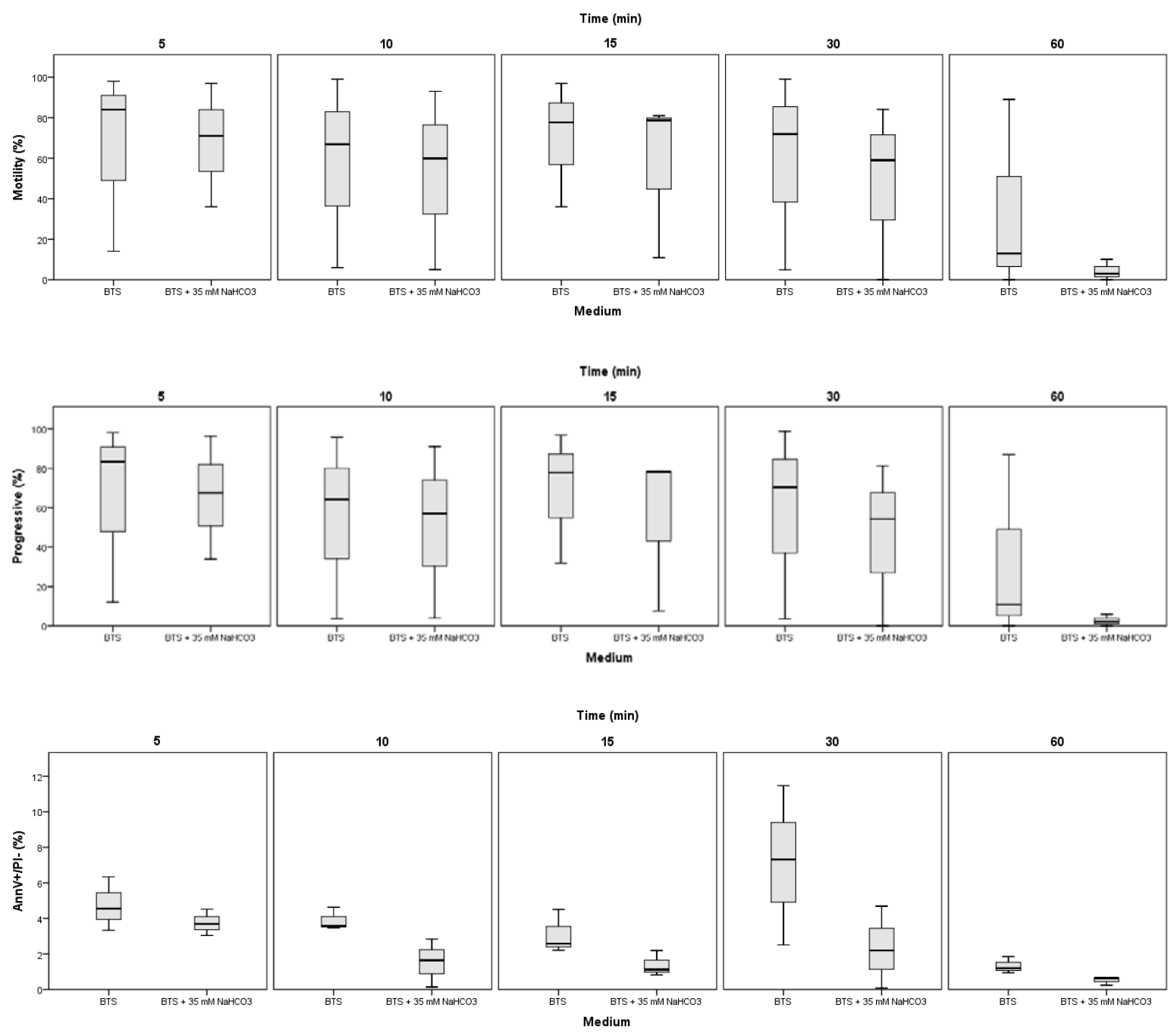
Set of graphs 2. Effect of different concentrations of exogenous progesterone on boar sperm variables (total motility (\%), progressive motility (\%), dead sperm with damaged acrosomes (PNA+/PI+), sperm viability (PNA-/PI-) and mitochondrial integrity (MT+/PI-) over incubation time.
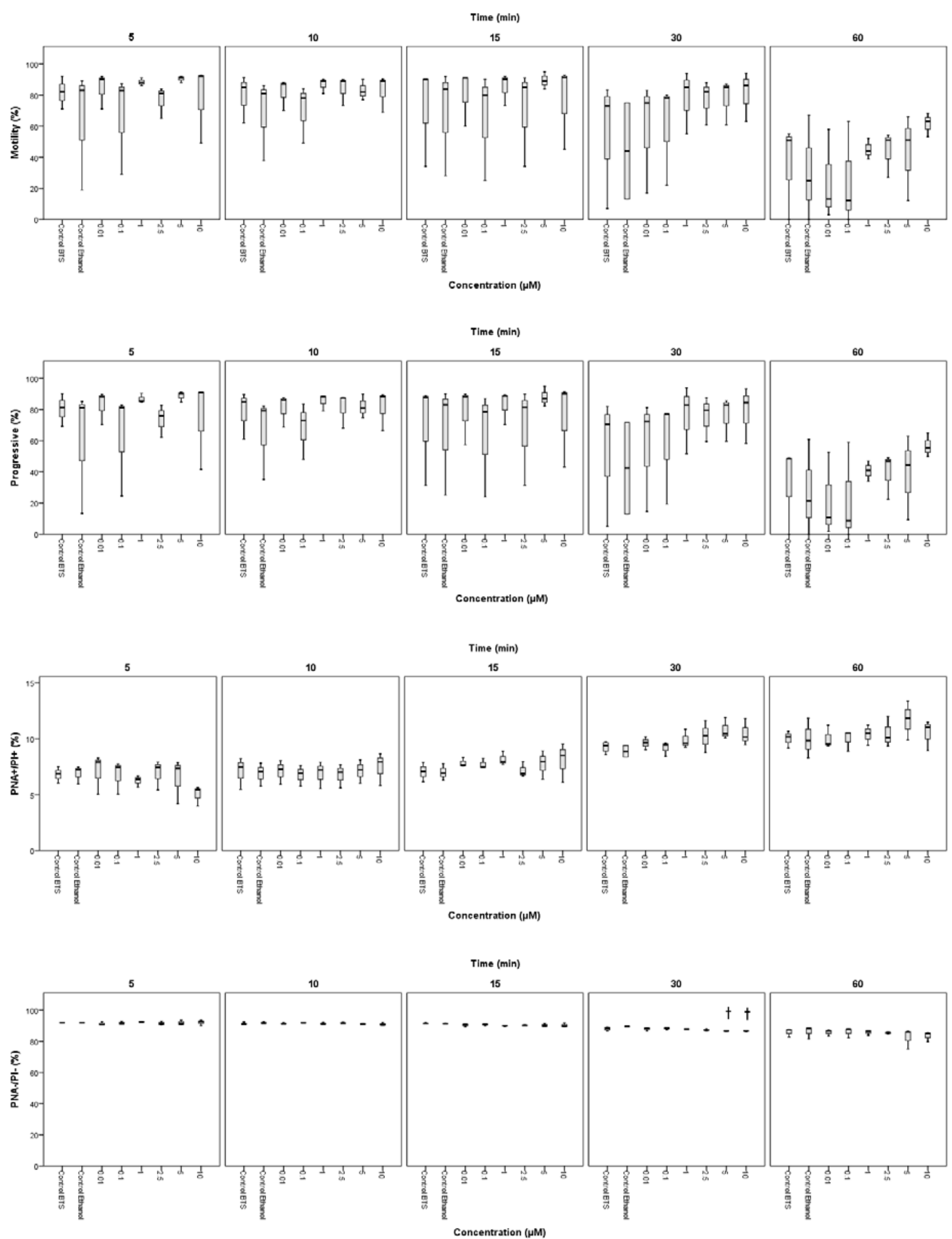


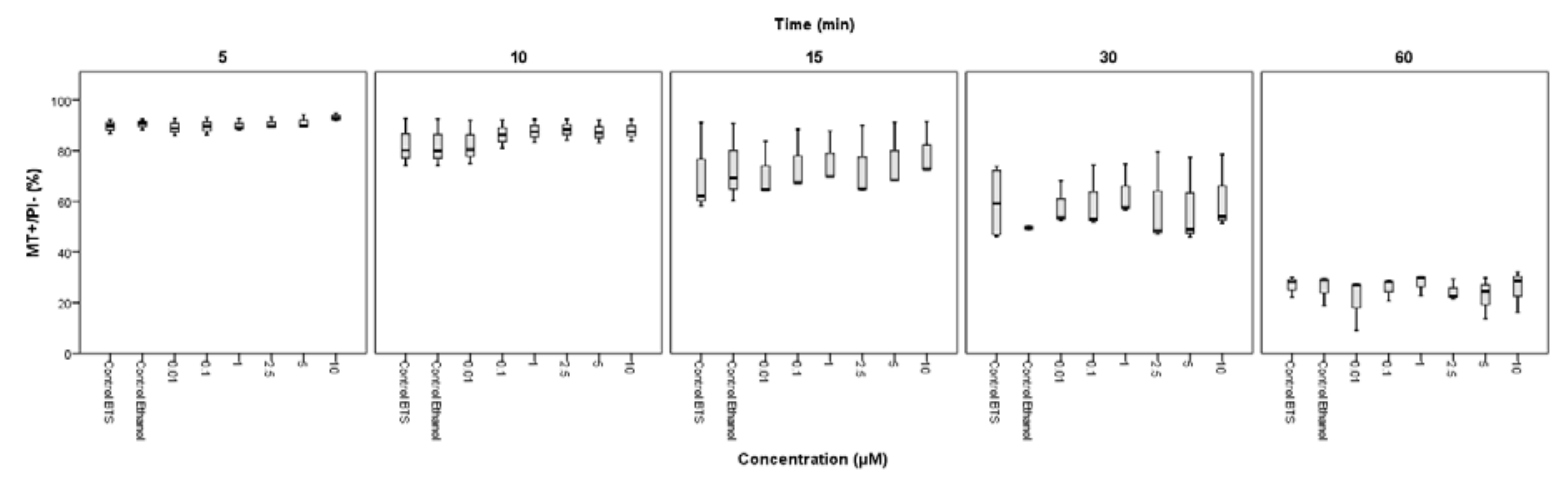


Set of graphs 3. Effect of different concentrations of mibefradil on boar sperm variables (total motility (\%), progressive motility (\%), dead spermatozoa with damaged acrosomes (PNA+/PI+), sperm viability (PNA-/PI-) and mitochondrial integrity (MT+/PI-) over incubation time.
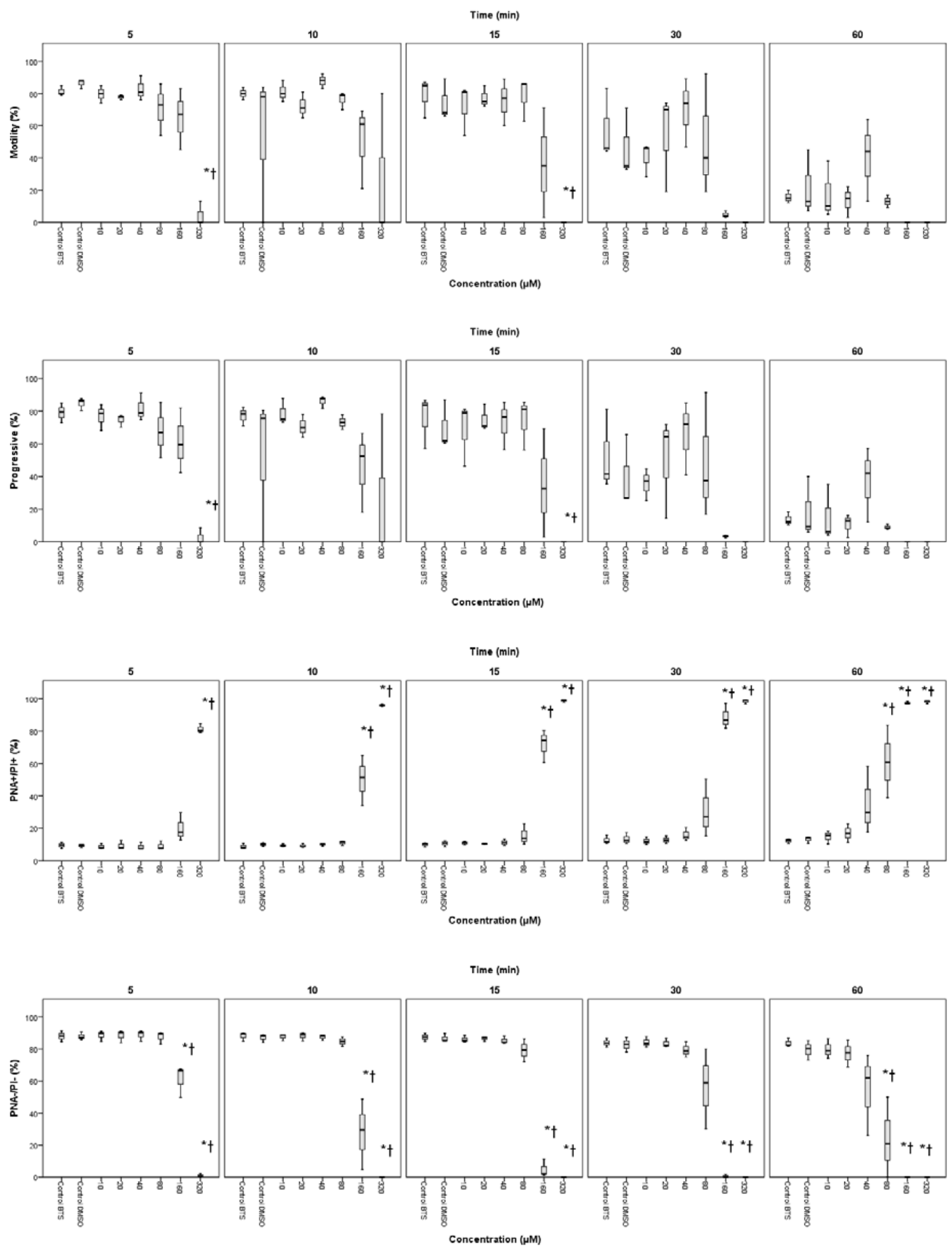


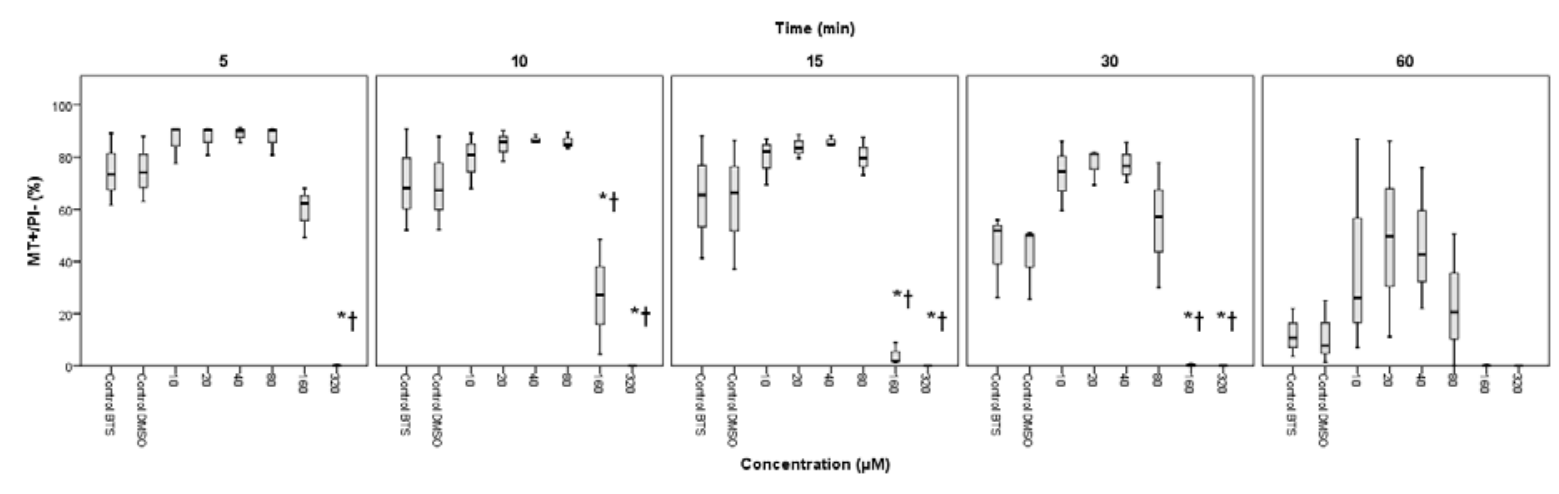


Set of graphs 4. Effect of different concentrations of NNC 55-0396 on boar sperm variables (total motility (\%), progressive motility (\%), dead spermatozoa with damaged acrosomes (PNA+/PI+), sperm viability (PNA-/PI-) and mitochondrial integrity (MT+/PI-) over incubation time.
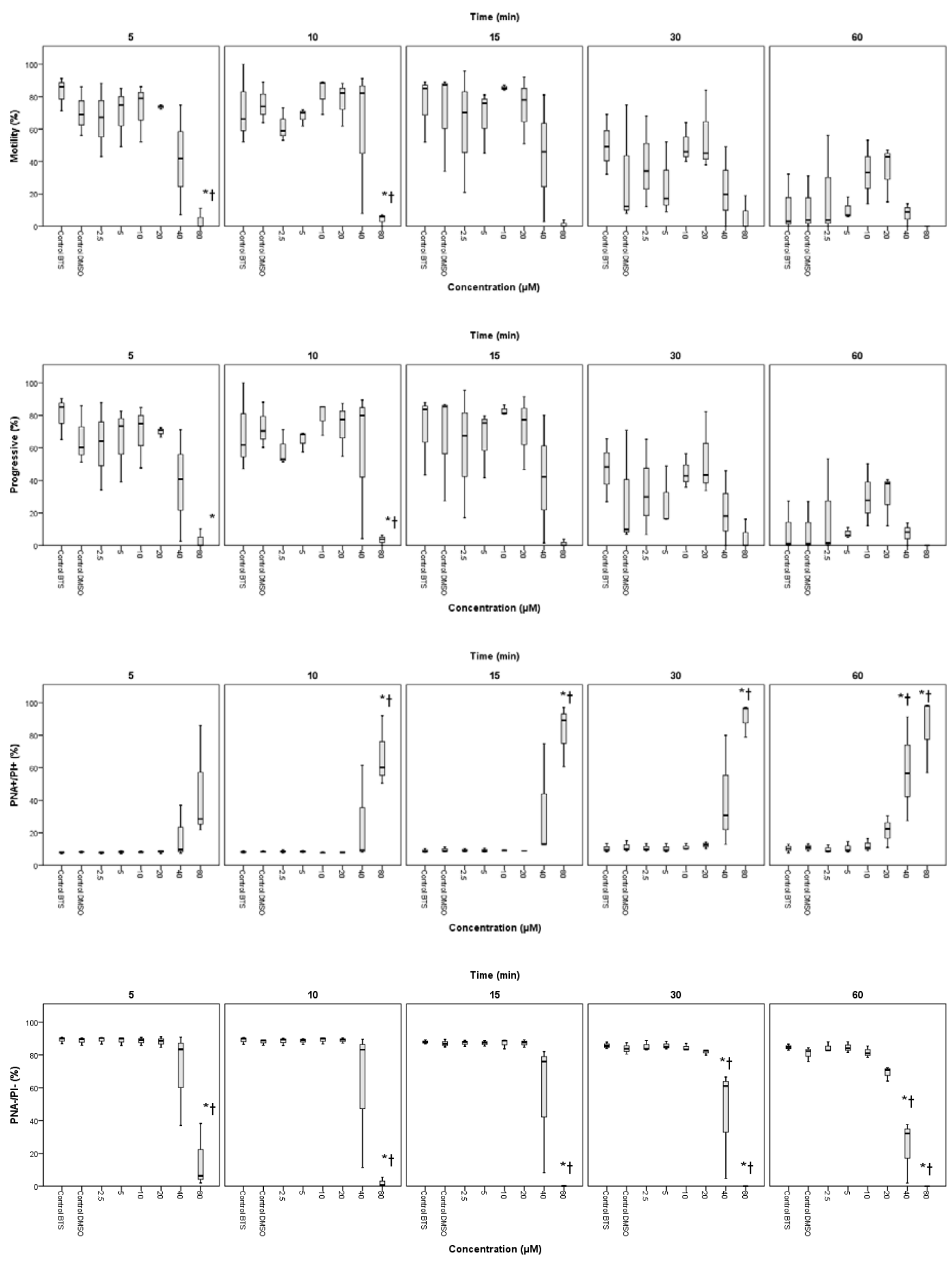


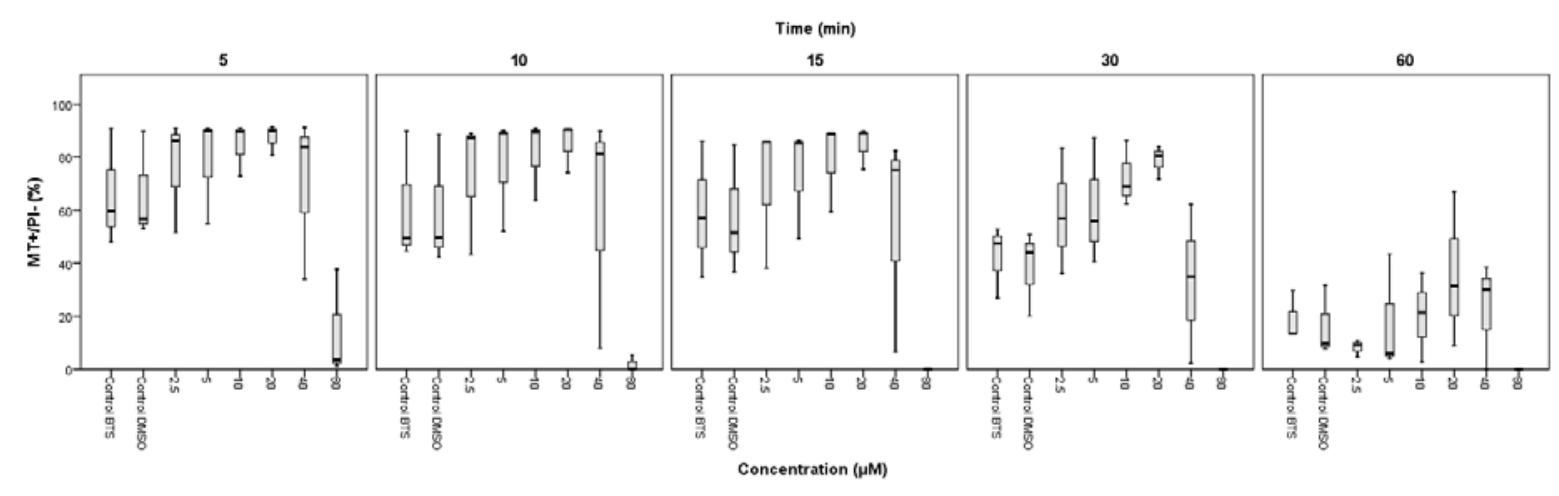


Set of graphs 5. Effect of the increased availability of $\mathrm{Ca}^{2+}$ in Control BTS, BTS without EDTA, and BTS without EDTA with addition of capacitation levels of sodium bicarbonate (35 mM of $\mathrm{NaHCO}_{3}$ ) on sperm variables (total motility (\%), progressive motility (\%), dead sperm with damaged acrosomes (PNA+/PI+), sperm viability (PNA-/PI-) and mitochondrial integrity (MT+/PI-) over incubation time.
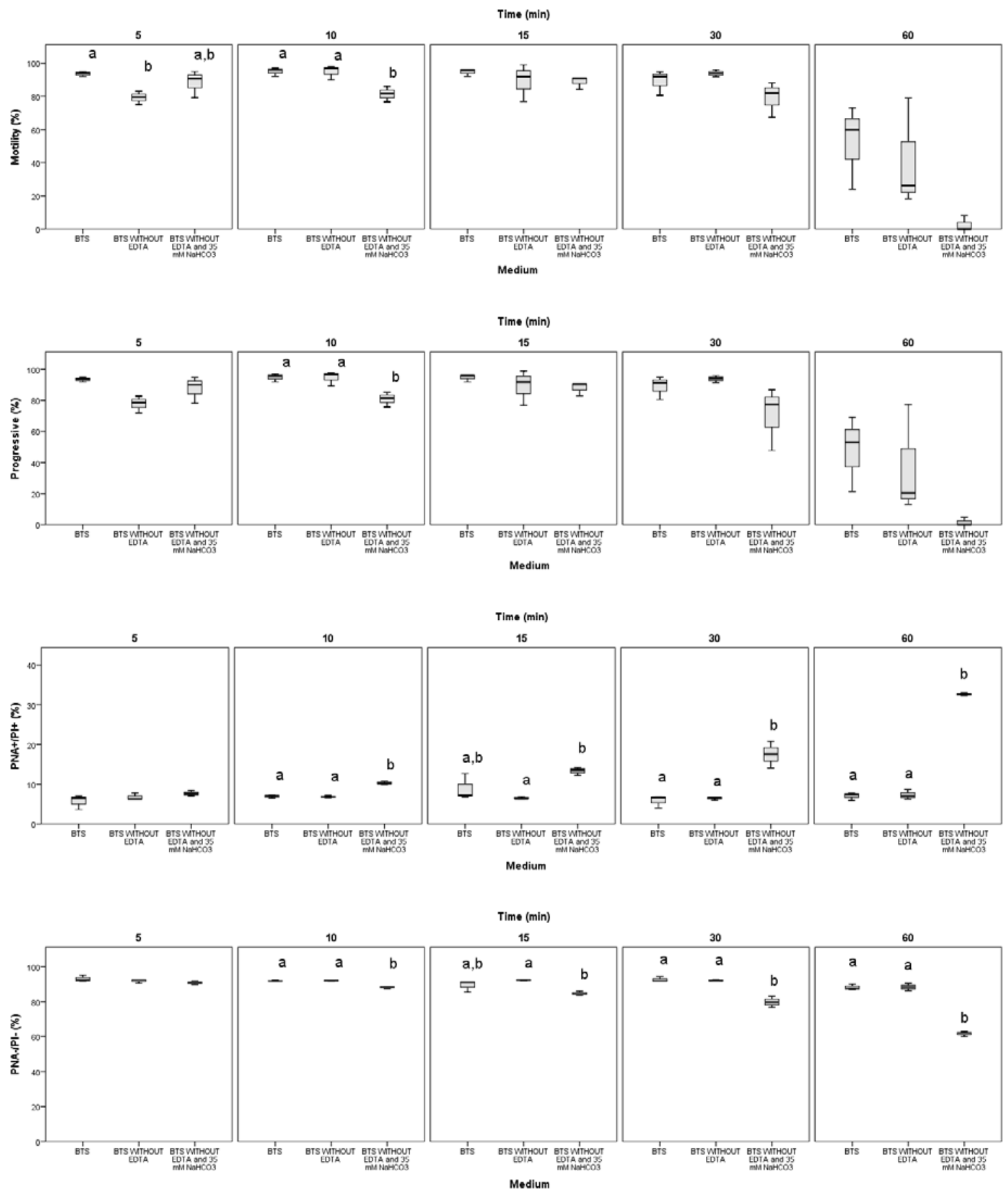


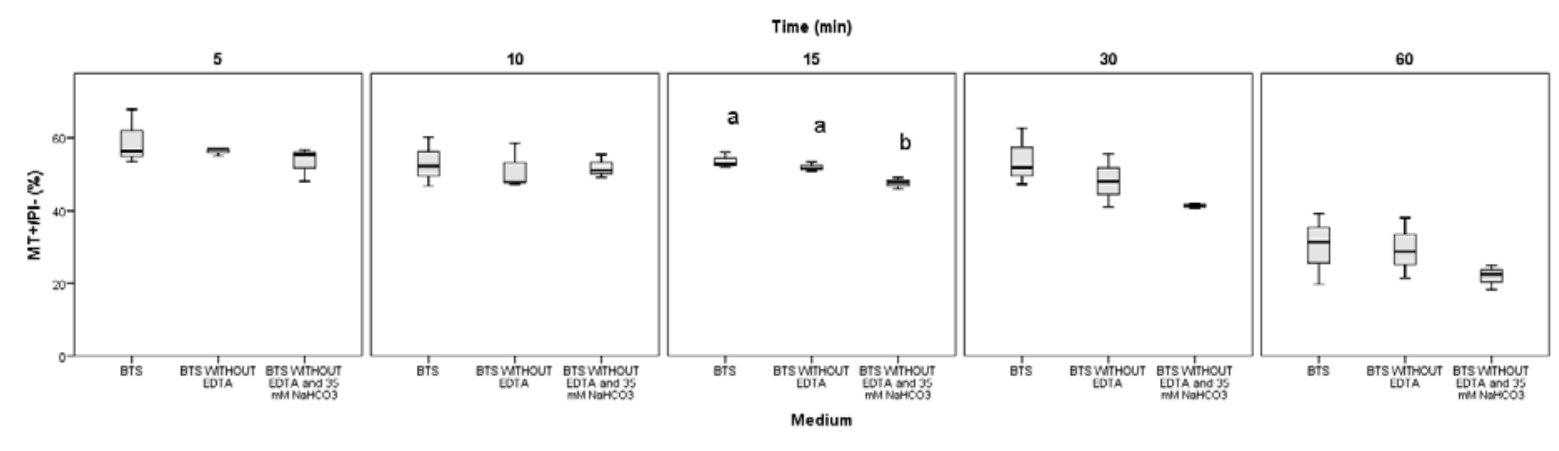


Set of graphs 6. Sperm changes (total motility (\%) and progressive motility (\%)) following addition of either $0.01 \mu \mathrm{M}$ or $10 \mu \mathrm{M}$ progesterone after pre-incubation of boar spermatozoa in capacitating medium at $38{ }^{\circ} \mathrm{C}$ for $30 \mathrm{~min}$.
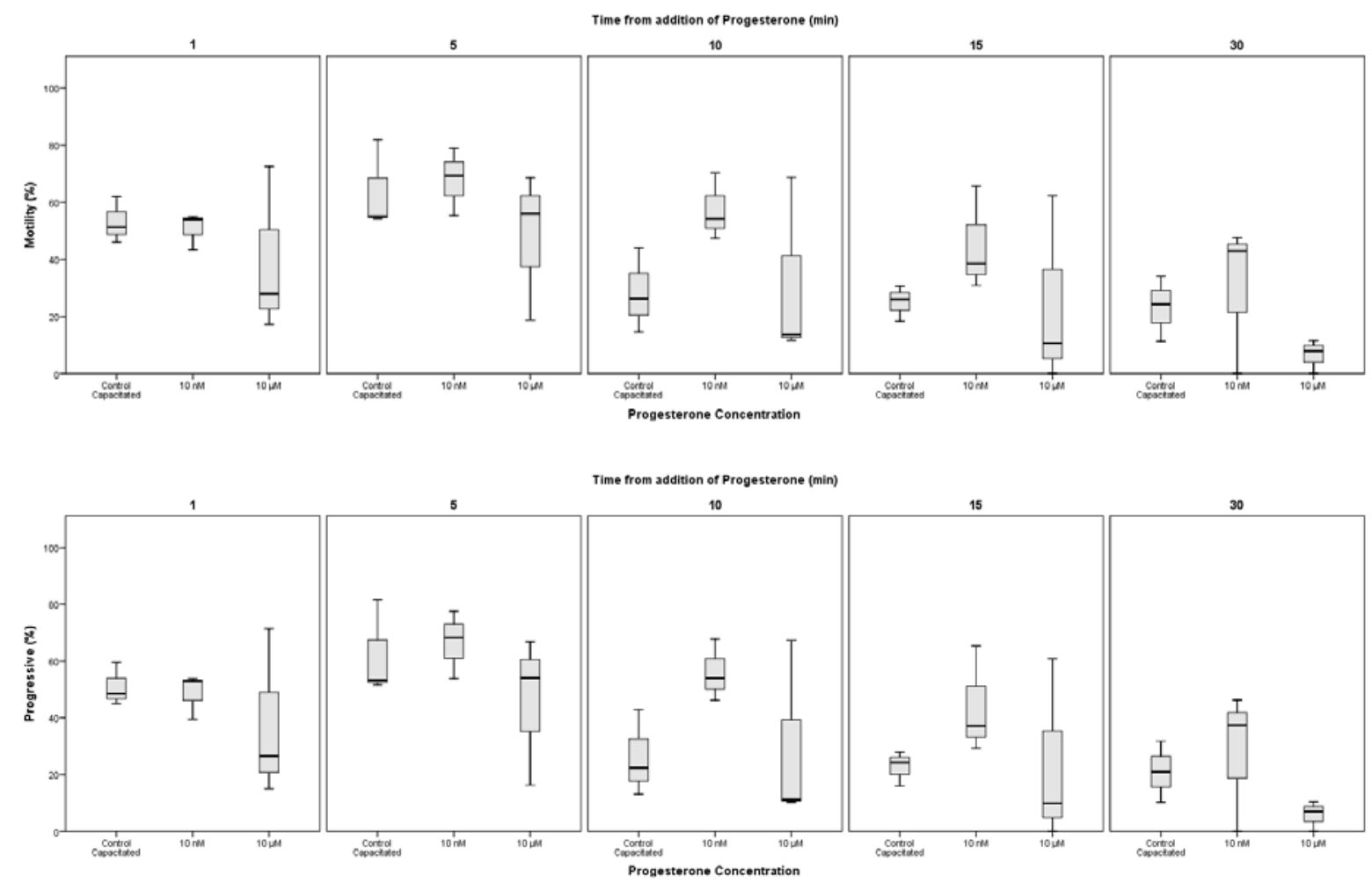